Portland State University

PDXScholar

5-6-1968

\title{
Child Care Arrangements in Affluence and Poverty
}

Josephine Jeannette Gurrola

Portland State University

Joan Beck Hansen

Ruth Townsend Hardy

Donna Mae Landye

Sandra Mae Poirier

Follow this and additional works at: https://pdxscholar.library.pdx.edu/open_access_etds

Part of the Social Work Commons

Let us know how access to this document benefits you.

\section{Recommended Citation}

Gurrola, Josephine Jeannette; Hansen, Joan Beck; Hardy, Ruth Townsend; Landye, Donna Mae; and Poirier, Sandra Mae, "Child Care Arrangements in Affluence and Poverty" (1968). Dissertations and Theses. Paper 492.

https://doi.org/10.15760/etd.492

This Thesis is brought to you for free and open access. It has been accepted for inclusion in Dissertations and Theses by an authorized administrator of PDXScholar. Please contact us if we can make this document more accessible: pdxscholar@pdx.edu. 


\section{AN ABSTRACT OF THE THESIS OF}

$\frac{\text { JOSEPHINE JEANNETTE GURROLA, et al. for the }}{\text { (Name of student) }} \frac{\text { MASTERS }}{\text { (Degree) }}$ in SOCIAL WORK (Major) presented on May 6, 1968 (Date)

Title: CHILD CARE ARRANGEMENTS IN AFFLUENCE AND POVERTY

Abstract approved:

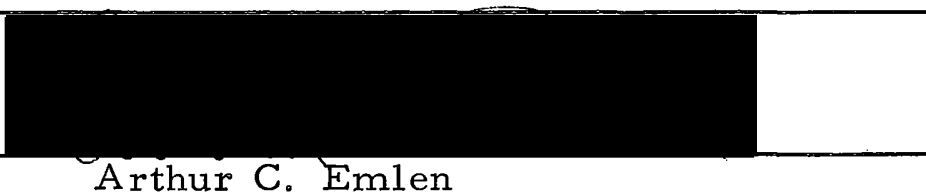

A study of the attitudes of 40 mothers toward their child care arrangements tested hypotheses concerning the conditions of eco:nomic and child care necessity under which mothers of two socioeconomic groups would be satisfied with their arrangements. It was hypothesized that the satisfaction with an arrangement would be associated inversely with economic necessity and child care necessity. A prediction was also made that the mothers' expressive satisfactions with the child care arrangements (benefits to the child and relationship to the sitter) would only be realized after the instrumental necessities of convenience and dependability of the arrangement were met.

Interest in this study developed from Perry et al. (1967) where satisfaction with child care arrangements of employed mothers was studied. However, this study broadened the area of investigation 
to include all mothers using child care arrangements.

A sample of 40 mothers was chosen, 20 from an upper middle class residential area, and 20 women receiving Aid to Dependent Children. The attitucies of these women were assessed through an interview schedule, a Likert scale of satisfaction items, and an independent rating by the interviewer. Four case studies of two mothers from each group were used to enrich the study with further descriptive data on the respective life styles of the two socioeconomic groups.

No difference was found between the two samples in the level of satisfaction with the child care arrangement. However, the groups did differ in the pattern of satisfactions reported. Guttman scale patterns of the four subscales (convenience, money, benefits to child, and relationship to sitter) were reversed for the two groups. This difference in patterns was interpreted as a reflection of the socioeconomic standing and life circumstances of the mothers. 
Child Care Arrangements in Affluence and Poverty

by

Josephine Jeannette Gurrola

Ruth Townsend Hardy

Joan Beck Hansen

Donna Mae Landye

Sandra Mae Poirier

A THESIS

submitted to

Portland State College

in partial fulfillment of

the requirements for the

degree of

Master of Social Work

June 1968 
APPROVED:
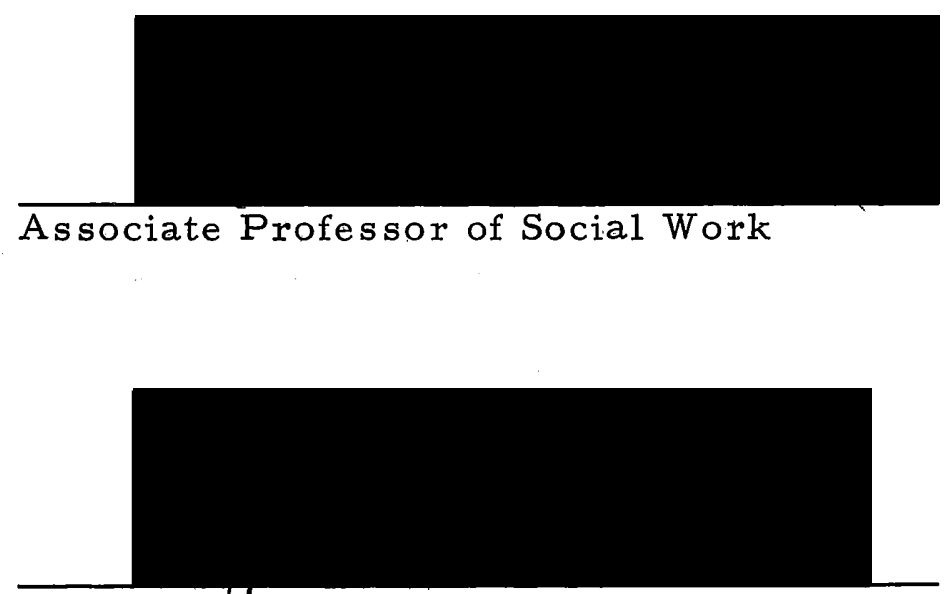

Dean, Sch $\varnothing 01$ of Social Work
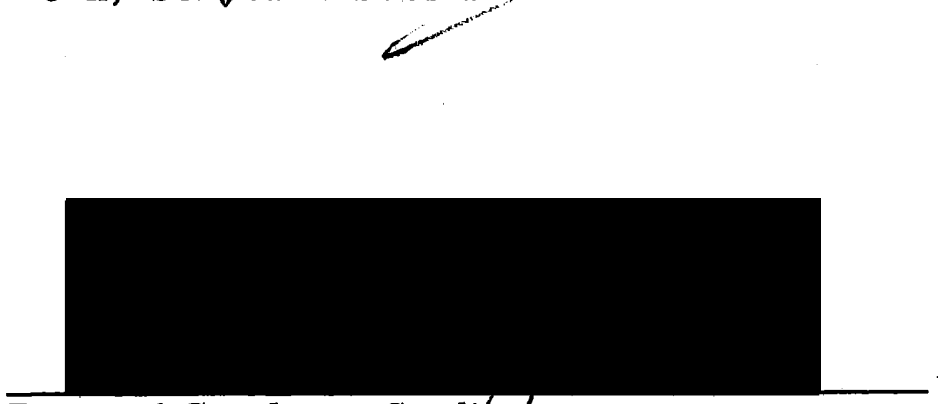

Dean of Graduate Studies

Date thesis is presented May 6, 1968

Typed by Barbara Glenn for Josephine Gurrola, et al. 


\section{ACKNOW LEDGEMENTS}

Our group is grateful for the help of the many people who made this study possible. We wish to thank Gordon Gilbertson, Administrator, Multnomah County Public Welfare Commission; John Burch, Assistant Administrator, Multnomah County Welfare Commission; and the caseworkers of this agency who assisted us in obtaining our sample of Welfare mothers. We would like to express our appreciation to those mothers of both the Welfare and Riverdale samples who gave so generously of their time.

To the personnel of the Neighborhood Family Day Care Project, we extend a special thank you for their patience and unspoken moral support. We are indebted to Pauline Robinson and Betty

Donoghue for assisting us in the compiling of necessary material for the study.

The group members thank Judy Fretta, for her genuine interest in the project and her clerical assistance throughout the year, and Pat Campbell for typing of the complete initial draft.

We appreciate the constructive criticism offered by Professors John M. Whitelaw and Merwyn Greenlick.

Above all, we thank Arthur C. Emlen, Associate Professor of Social Work, for his thought, skill, guidance, and unfailing enthusiasm in directing this project. His personal endurance coupled with 
his involvement in each phase of the project made it possible for us to complete this study. 


\section{TABLE OF CONTENTS}

$\underline{\text { Page }}$

I. FORMULATION OF THE PROBLEM I

Introduction 1

Scope and Focus 3

Summary of Method 8

Review of the Literature $\quad 10$

The Hypothesis $\quad 12$

$\begin{array}{ll}\text { II. METHOD OF STUDY } & 14\end{array}$

Rationale for Sample Selection $\quad 14$

Method of Obtaining Sample 16

Development of Measurement Devices $\quad 19$

Collection of Data 23

Evaluation of Scales $\quad 26$

III. FINDINGS $\quad 32$

Introduction $\quad \therefore \cdots . \quad 32$

A. Comparison of Affluent and Low-income
Families

B. Analysis and Discussion of Satisfaction Data 44

IV. FOUR CASE STUDIES 61

Introduction $\quad 61$

Riverdale - High Child Care Necessity $\quad 65$

Welfare - High Child Care Necessity 71

Riverdale - Low Child Care Necessity $\quad 74$

Welfare - Low Child Care Necessity 79

Conclusion $\quad 83$

V. CONCLUSIONS 91

Summary of Study $\quad 91$

Results and Conclusions $\quad 92$

Suggestions for Further Study $\quad 98$

Implications for Social Policy . 99

$\begin{array}{ll}\text { BIBLIOGRAPHY } & 101\end{array}$ 
TABLE OF CONTENTS (continued)

$\underline{\text { Page }}$

\section{APPENDICES}

Appendix A 104

Appendix B

107

Appendix C

108

Appendix D

109

Appendix E

115

Appendix $F$

118

Appendix $G$

121

Appendix $\mathrm{H}$

125

Appendix I

126

Appendix $\mathrm{J}$

134 


\section{LIST OF TABLES}

$\underline{\text { Page }}$

I. Satisfaction with Convenience of Arrangement 27

II. Satisfaction with Relationship to Sitter 27

III. Satisfaction with Benefits to Child 28

IV. Satisfaction with Money 29

V. Families with Husband in the Home 33

VI. Residence at Current Address 36

VII. Nursery School Experience 39

VIII. At-Home Child Care Arrangements 39

IX. How Current Arrangement Located 41

X. Who Provides Care in Current Arrangement 41

XI. Satisfaction with Benefits to Child 45

XII. Satisfaction with Relation to Sitter 46

XIII. Satisfaction with Convenience of Arrangement 47

XIV. Satisfaction with Money Paid for Sitter 48

XV. Pattern of Satisfaction for the Welfare Mothers: A Guttman Scale $\quad 50$

XVI. Pattern of Satisfaction for the Riverdale Mothers: A Guttman Scale

\section{APPENDIX TABLES}

XVII. Judges' Rating of Content Items 116

$\begin{array}{ll}\text { XVIII. Size of Families } & 126\end{array}$

XIX. Age of Fathers 126 
LIST OF TABLES (continued)

$\underline{\text { Page }}$

XX. Educational Level of Fathers 126

$\begin{array}{lll}\text { XXI. Training of Riverdale Fathers } & 127\end{array}$

XXII. Employment of Riverdale Fathers $\quad 127$

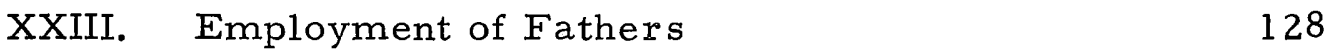

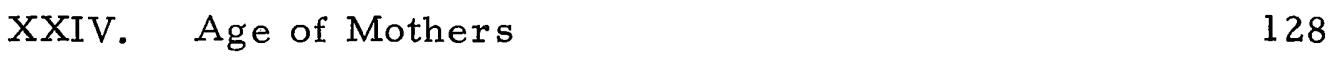

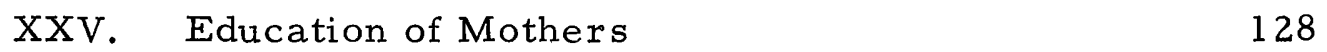

$\begin{array}{ll}\text { XXVI. Check List of Conveniences } & 129\end{array}$

$\begin{array}{ll}\text { XXVII. Conveniences Volunteered by Respondents } & 129\end{array}$

XXVIII. Length of Residence at Current Address $\quad 130$

XXIX. Historical Data: Child Care Arrangements Used

XXX. Current Child Care Arrangements 131

XXXI. Current Child Care Need 131

XXXII. How Current Arrangements Located 132

XXXIII. Transportation Patterns in Child Care Arrangements

XXXIV, Mothers' Perceptions of Reasons for Ease in Making Child Care Arrangements

XXXV. Mothers' Perceptions of Reasons for Difficulty in Making Child Care Arrangements

XXXVI. Satisfaction with Arrangements by Child Care Necessity

XXXVII. Satisfaction with Arrangements by Number of Children in the Family 
LIST OF TABLES (continued)

Page

XXXVIII. Satisfaction with Arrangements by Number of Children under Six in the Family

XXXIX. Satisfaction with Arrangements by Number of Hours Per Week of Substitute Child Care

XL. Satisfaction with Arrangements by Child Care Resources in Household 


\title{
CHILD CARE ARRANGEMENTS IN AFFLUENCE AND POVERTY
}

\author{
CHAPTER I
}

\section{FORMULATION OF THE PROBLEM}

\section{Introduction}

This report describes a study of attitudes of mothers toward their arrangements for substitute child care. The aim of the study was to test and develop some ideas about the conditions under which mothers will be satisfied with their child care arrangements.

More specifically, the study was concerned with the relative importance to mothers of the convenience of arrangements and of the dependability of the child care person. It was assumed that these instrumental values of the arrangement tend to take precedence over the value of the benefits to the child. It was believed that the child. oriented value of an arrangement would tend to assume importance to mothers only after the demands of necessity are satisfied.

To test this idea, the life circumstances and attitudes of two dramatically different socioeconomic groups were studied--an affluent group and a poverty-level group. These were discrete, criterion groups of low and high economic need. It was assumed that high family income provides a rich complement of conveniences and resources that facilitate the making of child care arrangements. 
These women have an advantage in the market place when they shop for a child care arrangement; and they are under less pressure to make unsatisfactory arrangements.

This hypothesis arose out of previous work of Emlen (1967) and Perry et al. (1967). Perry et al. found that working mothers who reported feeling compelled to work and to take what they could get in a babysitter, made arrangements with which they were dissatisfied and which were of short duration.

It was not expected, however, that the attitudes in question could be predicted as strongly from the degree of economic necessity by itself as from the combination of economic necessity and child care necessity. Child care necessity is the child care needs of the family as indicated by the number of children for whom substitute care is needed, in relation to the number of available child-caring persons within the family. These two kinds of necessity were hypothesized as objective life circumstances that strongly determine child care behavior and attitudes. Child care necessity is basically a reality of family composition, and the importance of this predictor variable in the study is supported by cross-cultural studies of the antecedents of child-rearing attitudes and practices (Minturn and Lambert, 1964).

The present study added new perspective to previous work on the problem by attempting to link the degree of the mother's 
satisfaction with the arrangement to objective life circumstances. One would expect that their respective life circumstances would set realistic constraints upon the alternatives open to mothers and would affect the freedom of choice mothers believe they have in making arrangements. In testing the assumption that mothers operate on the basis of a hierarchy of values or needs (Maslow, 1963) in making child care arrangements, it was predicted that mothers would tend to report satisfaction with benefits to the child only if in general they also reported satisfaction with convenience factors in the arrangement.

The preceding formulation of the problem is summarized in Figure 1 .

\section{Scope and Focus}

The study concerned the mother and her attitudes towards the satisfactions of the child care arrangements she made. The research group recognized that at least three persons were involved in a child care arrangement: the child, the mother, and the sitter. Interest was centered on the mother's attitude toward the satisfactions of the child care arrangements because she was viewed as the selector of substitute child care in most instances. The mother is the primary giver of child care in the family unit and whenever she must be away from the child she must find some other form of care 
PREDICTOR

VARIABLES

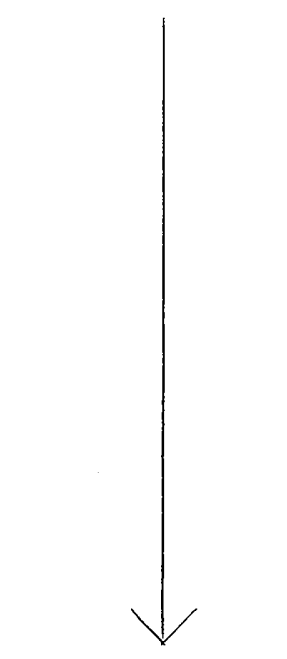

CRITERION

VARIABLES
THEORETICAL

CONSTRUCTS

EMPIRICA L

INDICANTS

Economic Necessity

Child Care Necessity

(Inverse relationship)
Criterion groups based on income:

Riverdale families

ADC families.

(1) Number of children,

(2) Number of children under age 6 ,

(3) Number of hours child care needed,

(4) Number of resources for child care in the home.

Likert Scale with 4 subscales: convenience, money, benefits to child, mother sitter relationship.

(c) benefits to child

(d) mother-sitter relationship

VALIDATION

DATA

(1) 4 case studies,

(2) Interview descriptive data on life styles.

Figure 1. Relationship between Variables. 
for the child.

The terms "child care arrangement" and "sitter" were used interchangeably throughout the study. A child care arrangement was defined as including any type of substitute child care. The term in cluded the following arrangements: the child remained alone to care for himself (a latch-key arrangement); the child was cared for by a peer or sibling; the child was cared for by the father or other relative or unrelated adult in the household; the child was cared for by an outside person coming into the home; the child was cared for out of the home by a relative or nonrelative; the child was cared for in a licensed or other group setting; the child attended nursery school. (Children who were attending regular school sessions, above the nursery or preschool level, were not considered to be receiving child care as the major function of school attendance was perceived to be education. )

There was no denial of the importance of the sitter or the child in the making and maintenance of any child care arrangements, but this study narrowed its focus to include only the attitudes of the mother for investigation.

The four satisfactions which were explored with the mothers were the convenience and dependability of the arrangement, the money or financial cost of the arrangement, the benefits to the child, and the personal relationship of the mother to the sitter in the child 
care arrangement used.

Rather than link the satisfactions to the mother's motivation to work or to be away from the home and/or the child, this study tried to relate the satisfactions sought to the mother's general lifecircumstances and her child care liabilities. The general life circumstances were defined as her socioeconomic status as reflected in her income level, residence, and general material conveniences which were available to her. The mothers saw conveniences in widely varying ways. "Morning nursery school and afternoon naps" or "a roof that doesn't leak" were seen as conveniences by the Welfare sample while the Riverdale women thought that "an electric broom" and various other acquisitions including "a live-in maid or babysitter" who was described as similar to Mary Poppins were their most prized conveniences. It was thought that those possessing more life conveniences would be in a more advantageous position to choose a sitter. Her child care liabilities were the perceived need for child care and the age and number of children related to the number of child care resources within the family unit.

As it was conceived, the study was directed towards the child care arrangements for preschool children; however, as the study evolved, all children in the household were considered in order to give the broadest possible picture of existing use of child care. All expressed need for child care was considered legitimate by the fact 
of its expression. Child care which was needed during any portion of the twenty-four hour day, or overnight, qualified for the study. The aim was to gather data on the mother's satisfactions in any type of a r rangement.

The mothers selected for the sample were a high socioeconomic group from the Riverdale Directory, a publication of the Riverdale School PTA, and a low socioeconomic group from the 1966 rolls of the Multnomah County Welfare Department. The rationale behind the choice of these two groups was the wish to obtain samples from two groups that clearly reflected different levels of economic need and resources. The study was to be unlike past studies that focused on the mother's need to work as the primary motive for seeking child care. In the total sample, the motives for using child care ranged from employment to recreation; community and social activities to education.

The U. S. Children's Bureau has supported research pertinent to the quality of care received by children who are cared for in the private homes of other women while their mothers work. These are the informal kinds of arrangements which are not licensed or supervised by public welfare or children's agencies. Three studies which have been conducted locally (Collins 1966, Emlen 1967, Perry et al. 1967) have been centered on this type of child care which is known as private family day care. The preponderance of 
the findings in these studies has been related to the formation and

continuation patterns of private family day carearrangements. This study was directed toward a survey of any arrangements used by mothers, regardless of the reason which caused the absence from the child. The use of a child care arrangement verified the existing need for one.

The present study was focused on the mother's satisfaction with the arrangement. The personality and role adjustments of the mother, the cooperation between the mother and sitter, the amount of dependency that either mother or sitter felt on the arrangement, the mother's ability to cope with difficult situations, and the continuity patterns of arrangements were all possible areas of investigation. Some of these areas were covered in a cursory manner during information gathering for the study; however, the major emphasis remained on the mother's satisfactions with the arrangements she made as they corresponded to her life circumstances.

\section{Summary of Method}

The mother's attitude toward her child care arrangement was assessed through the use of three separate devices: (1) direct questioning using an interview schedule, (2) completion of a scale of items by the mother, (3) an independent subjective rating by the interviewer of the mother's attitude toward the satisfactions of the 
arrangement. The interview offered a semi-structured opportunity for the mother to state which child care arrangements she preferred because of their inherent satisfactions. The interviewer used a schedule that provided open-ended and direct questions about satisfactions, life circumstances and life styles. The satisfaction scale was administered at the end of the interview. It was comprised of a set of statements written on cards which related to four separate content areas. These areas were: the convenience-dependability of the arrangement, the benefits to the child, the mother-sitter relationship, and money.

After each interview, the interviewer subjectively, assessed which of the three specific satisfaction areas each mother valued most in establishing and continuing her child care arrangements. In order to enrich the study further with descriptive data on the life styles of the two groups as they related to their child care arrangements, case studies were completed on four families. Two families were chosen within each socioeconomic group. The case studies focused on the mother's use of child care arrangements to balance her child care needs. Child care necessity was equated with the number and age of the children who needed care when the mother was away from them as it related to the possible alternative child care givers in the family unit. Each of the socioeconomic groups was subdivided according to their child care needs. From. Types 
I-IV in Figure 2, an individual illustrative case was chosen for the case studies.

CHILD CARE

ECONOMIC NECESSITY

HIGH

(Welfare)

HIGH

LOW
Type I

Type III
LOW

(Riverdale)

Type III

NECESSITY

Figure 2. Typology for Choosing Case Study Families.

\section{Review of the Literature}

The literature available deals primarily with the use of day care by working mothers or with care in group or agency settings. Perry et al. conducted a study in 1967 on the continuity of private family day care arrangements as associated with satisfaction with and dependence on the arrangement. This study used both mothers and sitters for questioning. No single study paralleled the present study because it attempted to assess the mother's attitudes toward the satisfactions of any child care arrangement regardless of her motivations for the use of child care. This study investigated the mother's ordering of the satisfactions of the arrangement in the light of her general life circumstances.

The child welfare field has gathered statistics concerning only 
those children whose mothers are employed. Of the 3.8 million children under six years of age whose mothers were employed in 1965, 78\% were cared for either by their mothers, in their homes, or by relatives. One percent remained by themselves, $15 \%$ were in private family day care, and $6 \%$ were in group day care centers. (Child Care of Nation's Working Mothers, 1965). According to these statistics, $94 \%$ of all the working mothers had made some type of private arrangement for the care of their children. The paucity of knowledge concerning what types of arrangements mother looked for, and why, indicated a wide open field for research. The Day Care Exchange Project (Collins, 1966), the Gerald Perry et al. study in 1967, and a survey by Joseph Perry in 1961 researched private family day care arrangements. All were oriented towards the working mother and her behavior in acquiring and keeping sitter arrangements. The Gerald Perry et al. study measured the mother and sitter satisfactions as they related to the continuity of the arrangements.

The present study dealt with the relative importance of the satisfactions derived by the users of any type of child care. It also differed from the Gerald Perry study because the data was not collected from both the giver and user of child care, but rather only from the user who was the mother seeking substitute care. New dimensions were gained for the present study by including in the 
survey any type of child care arrangement made by mothers for any reason.

\section{The Hypothesis}

Past research has avoided delving into the needs for substitute child care except that of the working mother. By omission, it has contended that the only problem in acquiring child care is for the mother who needs to work. Mothers, in general, use substitute child care which they acquire in a variety of ways. The area of interest for this study has been the difference between what the mothers of two widely different socioeconomic groups search for in respect to the satisfactions of their child care arrangements.

As shown in Figure 1, the principal predictor variable was the socioeconomic status of the two samples. The criterion variable was the satisfaction with the arrangements made as measured by the interview, the scale, and the interviewer's rating.

The hypotheses were:

(1) that economic necessity is inversely related to satisfaction with the child care arrangement;

(2) that child care necessity is inversely related to satisfaction with the child care arrangement; and,

(3) that economic necessity is associated with a hierarchy of value and satisfaction, such that mothers tend to place 
satisfaction with convenience factors before benefits to the child.

Specific research objectives included:

(1) developing attitude scales to measure the degree of satis faction in four discrete content areas--with special attention to (a) convenience and dependability and (b) benefits to the child.

(2) assessing the validity of the scale by comparing the scores for the satisfactions with the answers to the direct ques tioning of the interview schedule and the interviewer's subjective judgments.

(3) testing the above three hypotheses for the two sample groups. 


\section{CHAPTER II}

\section{METHOD OF STUDY}

This chapter describes the selection of the sample, the development of the instruments for measuring the theoretical concepts, the method of presenting the instruments to the respondents, and the evaluation of the data for reliability and validity.

\section{Rationale for Sample Selection}

To test the hypotheses and as sumptions, two comparisongroups were sought that would differ widely in the degree of economic necessity impinging upon everyday family life and upon the child care arrangements. The two primary criteria of sample selection, then, were (1) some child care need and (2) either high or low economic need.

The child-care criterion was based on presence in the home of at least one preschool youngster for whom, presumably, child care arrangements would be made. The economic criterion was satisfied by selecting a sample from two groups of widely divergent income levels. One group of mothers lived in a residential area in which family income is well above average, while the other group of mothers were from families receiving Aid to Dependent Children (ADC). 
ADC families from the Multnomah County Welfare Department were chosen to represent low income or high economic necessity. Income for persons on welfare varies according to number and ages of children in the family. It may be less than $\$ 100$ monthly for a mother with one baby up to $\$ 500$ or more for a family of 16 persons. The average is approximately $\$ 35$ per person per month. Families from Multnomah County were selected as most feasible for this study. Although it could be as sumed that the group of Welfare respondents would be homogeneous with respect to economic circumstances, we expected divergence within this group with regard to the number and ages of children in the family and the number of parents available to provide child care.

The second group selected for study was the inhabitants of the Riverdale SchoolDistrict. This is census tract 63 between Portland and Lake Oswego. It is bounded also by the Willamette River and Lewis and Clark College. It is a restricted residential area in which the median income in 1959 was $\$ 8,258$ compared to a median income level in Multnomah County for the same year of $\$ 6,000$. A third of the residents had incomes of $\$ 15,000$ and above and one-half had incomes of $\$ 10,000$ and over. Inspection of the housing within this census tract suggested that the Riverdale area is probably above average in income even within the census tract cited. This was our affluent group reflecting a contrasting life style to that of 
the Welfare group. Riverdale residents clearly represented a criterion group of high family income or low economic necessity.

\section{Method of Obtaining Sample}

Welfare Sample

With the help of the Assistant Administrator of Multnomah County Rublic Welfare Commission and the county casework staff, we were able to locate the desired sample, $\mathrm{N}=20$, of public welfare recipients to interview for the study. In early 1967, a list of Aid to Dependent Children families active in December of 1966 had been compiled. The list contained 3,824 families and contained additional helpful information such as whether the head of the household was employed and/or in training and the names and ages of children in the family for which public welfare was granted. Since this list was composed of active cases in December, it contained a higher proportion of two-parent families than might have been true if the sample were selected from a list of active cases taken during the summer and fall months due to Oregon's policy of extending assistance to families on the basis of unemployment of one or both parents. This list was narrowed to 140 families by a process of eliminating those without preschoolers as the list was reviewed. The list of 140 was referred to the Central Registration Department of the 
Welfare office to determine which families were still active, and to identify the caseworker. Of the 140 families, 98 were still active. Fifteen of these were eliminated because of current assignment to special units due to such reasons as need for foster care. The life circumstances of these families requiring special services was regardedas too deviant to include in our study of child care needs and satisfaction with child care arrangements. From a table of random numbers, the remaining sample was reduced to 36. Although only one month elapsed from the time this sample was identified until caseworkers were contacted by the interviewers, six families had moved, two could not be located and three families did not wish to participate. This narrowed the selection to a possible $\mathrm{N}$ of 25. Prior to interviewing, we had anticipated the public welfare sample would be quite accessible due to the intermediary, the caseworker. This was immediately found to be an optimistic assumption and many hours were spent attempting to locate families at home. The families had been mailed introductory letters (see Appendix III) and many caseworkers informed families of the purpose of the interview. As most of the families had no telephones so that appointments for the interview could be scheduled, it was very difficult to make contact with them. The difficulty was further complicated by the widespread geographic area covered by the final sample. As a result, availability of the families directly affected sample selection. 
It is possible that the five families not contacted were frequently away from home and therefore had radically different child care needs and resultant satisfactions than that of the families we were able to contact and interview.

\section{$\underline{\text { Riverdale Sample }}$}

The Riverdale group was selected from the Riverdale School Directory which lists all the families in the school district and is available from the school office. From the directory list of 442 families, a sample of 34 families was identified by a resident of the area who was familiar with the families. They were selected on her judgment as to whether they would be willing to participate and also on the basis of having a preschool youngster in the home. This was done by selecting families alphabetically from the directory who seemed to meet these criteria. As the selection was not randomly done, it may contain bias in the direction of identification of families who are above average in their participation in community affairs. The decision to make the selection in this non-random fashion was dictated by consideration of feasibility.

Initially, 28 families were identified. We were unable to contact some of the families and others did not wish to participate, necessitating the selection of six additional names for the sample unit. Contact with these families was relatively easy as the 
geographic area was limited and all the respondents had telephones. Because of the restricted area and the apparently high degree of communication among the residents, some of those last contact had heard of the study from neighbors. Difficulty in contacting the se families was in locating them at home and in arranging a mutually acceptable appointment date. From the list of 34 families, all those families who could be contacted and who agreed to be interviewed were used for the $\mathrm{N}$ of 20 . Again, it is possible that those families that could not be contacted had unique child care needs.

For both groups, the interviewer made at least two attempts to contact the family before discarding the name from the sample. In one case, five attempts were made prior to moving on to the next name on the sample list.

\section{Development of Mea surement Devices}

In order to compare general life circumstances with satisfactions in the areas of child care arrangements, three devices were used. The first was a questionnaire designed to secure information regarding general life style. (See Appendix D). Items for the questionnaire were selected from similar questionnaires used in

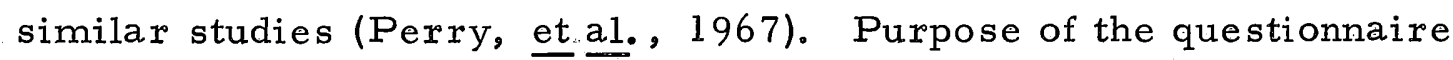
items was to get a wide picture of general life style of the respondents to determine the facilitating resources providing for 
convenience. It was intended to measure both the objective circumstances and the subjective evaluation of these circumstances by the respondent. The questionnaire consisted of seven pages and called for 16 responses to open-end questions. It was designed so that it began with questions about the household composition and proceeded to ask about conveniences available to ease the child care burden. This elicited responses about availability of child care in the family and attitudes about life style. The next section covered child care arrangements used and the amount of time involved. This was followed by a question intended to measure degree of urgency of child care need--"If your child is ill, what happens? You go anyway, miss, but not too often, etc." The respondent was next asked to name a reasonable fee. She was also asked to name the most satisfactory arrangement she had used. She was to indicate whether securing child care was easy or difficult and in her judgement what made it so. The focus then changed to the most current arrangement and the respondent's feeling about it in terms of likes and dislikes, how it was made, how long used and cost. Other questions about the current arrangement such as who transported the child, availability and convenience were posed. It was assumed that the fact of use was indicative of need. The mother's perception in the area of satisfactions with child care arrangements was accepted as valid as she is the primary arranger for substitute child care and her evaluations 
of satisfactions will influence the choice of arrangements made.

Thirty-six card items were selected to measure satisfactions. Items were selected from a pool of items developed by Perry, et al. (1967), and expanded by the Field Study (Emlen, 1967). These items were adapted to meet the needs of the current study and to them were added items of our own. Three content areas were conceptualized and 12 items per subscale were selected to be classified by judges as to fit in the content areas and whether they represented the conceptualized categories (see Appendix F).*

To pretest the card items, the statements used were presented to ten judges who were asked how well each item represented the conceptualized categories. The ratings were 0 (doesn't apply), 2 (slightly), 3 (perfectly). The convenience category: was divided into convenience and dependability as it seemed to have two different meanings.

The first four judges used were mothers and the second six were either unmarried or were fathers. This was done since the mothers seemed to have difficulty judging the items objectively without identifying with their role as mother and child care user. A comment from one was that she must be a bad mother as she hadn't considered any of these statements since she initiated use of the

* Originally the three money items were included in the convenience scale, but were separated out because of their manifestly different content. 
"latch-key" method. After a redefinition of the expectations, she asked to have the statements repeated, but she continued to find dif ficulty judging the items.

The six judges who were not mothers seemed better able to judge the items objectively and rate them according to category fit.

All but two of the questions were judged to fit one and only one of the three areas. Of the two items omitted, one statement pertained to resources within the household rather than satisfaction. The other was so ambiguous it was attributed by the judges as belonging to various areas. From the pre-test, 12 items were judged to test convenience-dependability satisfactions, 12 items, benefits to child and 8 items, mother-sitter relationship. Three items fit the satisfaction with money category. There was $94 \%$ agreement on classification of the items as fitting their category at least partially and fit their category better than any other category. (See Appendix E)

The third device used was a case study of four of the families initially interviewed. Details of the se case studies will be presented in Chapter IV. This method provided a holistic picture of the satisfaction with life style of these families and served to strengthen our confidence in the other devices used to measure satisfactions. 
Collection of Data

Interviewers were selected from the five-member thesis group on the basis of interest in this aspect of the study, feasibility, and skill. Three interviewers were selected. Two of these interviewers did ten interviews each, five from each group, and the other inter viewer did the remaining twenty interviews.

Interviewers were given a set of instructions regarding presentation of the questionnaire (see Appendix G)... It was suggested that responses be recorded on the left of the items and interviewer observations be recorded on the right. The questionnaire items were presented first followed by presentation of the card items. Except for informal discussion among the interviewers, no other interviewer training was undertaken.

Interviewers were not aware of the category fit of the card items so that interviewer bias could be controlled in this manner. Analysis of the scale data was not revealed to the interviewers until after the more open-ended interview data had been analyzed as another means of bias control. No other attempt was made to control for individual bias of the interviewers.

The respondents were all contacted by letter on the first contact (see Appendix II and III). The letter gave a brief overview of the purpose of the study and indicated that a phone call for an 
appointment would follow soon to determine the individual's willing ness to participate. This procedure was used for all respondents who had telephones. For those who did not have phones, a home visit was made to secure an appointment for the interview. Among the Welfare respondents, some were interviewed at the time of this visit, which was the first contact following the letter.

All interviews were held in the home of the respondents. A great deal of freedom was allowed with respect to others present during the interview so that in some cases the sitter was present and in many cases the preschooler in the family was present throughout the interview. Frequently, particularly with the Welfare sample, the husband was present during part or all of the interview.

The interviews were begun with the interviewer explaining the purpose and scope of the study in general terms. When the respondent seemed ready: to proceed, the questionnaire was introduced with the explanation that to assess conveniences and child care needs, some facts about the family and the kinds of child care arrangements used were needed. This served to put the respondent at ease and to secure cooperation through use of non-threatening items. Method of proceeding from the general to specific arrangement most currently used served to focus attention on the card items. Interviewers were given a good deal of freedom in discussing each item on the questionnaire until the respondent seemed able to answer without 
difficulty. Recording of observations by the interviewers served to establish accuracy of understanding of the questionnaire items on the part of the respondents.

The card items were presented on $3 \times 5$ cards in pre-established random order. They were numbered on the back so that they were presented in the same order to each respondent. Interviewers held the cards, read the item, then handed the card to the respondent who had been instructed to place it on the envelope which seemed most appropriate to her situation. Seven envelopes were used. The envelopes were labeled "Strongly disagree", "Disagree", "Slightly disagree", "Neither agree nor disagree", "Slightly agree", "Agree", "Strongly agree". They were arranged left to right in the order given. Reading aloud to respondents helped to clarify meaning for those items which were difficult in content or construction. Although clarification of items was done, care was taken to avoid leading the respondent. This procedure seemed to reduce the error with which respondents indicated their attitude and selected the correct envelope.

The interviews varied in length from 45 minutes to two hours depending on the apparent need of the respondent to discuss the study or her own feelings at greater length. Respondents were thanked both verbally and in writing for their participation and cooperation in the study. They were informed that a summary of the findings 
would be sent when the data had been compiled.

\section{Evaluation of Scales}

The final scales were arrived at through item-analysis procedures designed to yield scales that consisted of the best discriminating items. (Edwards, 1957). For each item the difference between the means of the highest and lowest quartiles of respondents was the measure used as the discriminatory power of the item. The function of this procedure was to eliminate those items that did not discriminate widely between those women who scored high and those who scored low on each item of the satisfaction scales. Items with a discriminatory power of less than 1.2 were eliminated. For a 7 -point scale, a larger discriminatory difference between the high and low means would have resulted in a more internally consistent summated scale. Of the 36 items presented to respondents, a total of 21 were retained for the improved scale. Money items were considered separately from the other data as they seemed to be of different quality.

The case study served as a form of retest in evaluating the reliability and validity of the test. Also, confidence in the validity of the test was supported by determining the relationship between responses to interview item 8 "What is a reasonable fee" and interview item 16. "What do you pay" and responses to scale items 8,11 , 
TABLE I

SATISF ACTION WITH CONVENIENCE OF ARRANGEMENT

\begin{tabular}{lccc}
\hline & D. P. & D. P. & D. P. \\
Item & $\mathrm{N}=40$ & Welfare & Riverdale \\
\hline
\end{tabular}

14. The babysitter lives too far
away to be convenient.
1.6
1.8
1. 7

16. I would be happier if I could
depend on my babysitter more. 1.9
1.8
1.2

28. I can drop my child off at the sitter's anytime I need to.
2.2
1.2
3.3

31. If I ever have to change my plans, she is very flexible about it.

1. 8

2. 8

1. 0

41. I can count on my sitter to let me know if she plans to go any place out of the ordinary with my child.
1.7
$\cdot 9$
1. 7

42. She's someone you can count on in an emergency.

1.4

1.3

1.3

TABLE II

SATISFACTION WITH RELATIONSHIP TO SITTER

\begin{tabular}{lccc}
\hline & D. P. & D. P. & D. P. \\
Item & $\mathrm{N}=40$ & Welfare & Riverdale \\
\hline
\end{tabular}

6. My sitter and I sit and talk to each other for hours.

2. 8

1. 2

1.6

9. She takes an interest in me personally.

2.3

1. 0

2. 8

18. I get tired of her telling me her problems.

2. $5 \quad 2.8 \quad 2.2$


TABLE II (continued)

\begin{tabular}{lccc}
\hline & D. P. & D. P. & D. P. \\
Item & N=40 & Welfare & Riverdale \\
\hline
\end{tabular}

26. Sometimes she ignores my instructions.

2.3

3. 0

2. 8

37. I feel she takes advantage of me.

1.2

3.2

.8

43. She often takes time to sit down and talk.

1.3

.6

1.8

TABLE III

SATISFACTION WITH BENEFITS TO CHILD

\begin{tabular}{lccc}
\hline & D. P. & D. P. & D. P. \\
Item & $\mathrm{N}=40$ & Welfare & Riverdale \\
\hline
\end{tabular}

5. She takes a real interest in my child.
2.4
1. 4
3.2

12. My child picks up bad habits at the sitter's.

1.3

1.6

1.8

17. I like the way she keeps the children clean.

1. 8

1. 4

1.8

21. My: child learns some important things he wouldn't learn at home by being with this sitter.
2. 1
1.6
2.2

24. My child is learning how to do things for himself at the babysitter's.
3. 0
2. 0
3.2

39. I wish my sitter would spend more time doing things with my child.
3. 4
3.6
3.4 
TABLE IV

SATISFACTION WITH MONEY

\begin{tabular}{lccc}
\hline & D. P. & D. P. & D. P. \\
Item & $\mathrm{N}=40$ & Welfare & Riverdale \\
\hline
\end{tabular}

8. I feel I am paying a reasonable fee for the care of my child.

$1.9 \quad 1.2 \quad .5$

11. Most babysitters want more $\begin{array}{llll}\text { money than I can pay. } & 3.3 & 2.2 & 2.5\end{array}$

35. I think that babysitters try to charge too much for their services.

2. 2

2.5 .7

The correlation coefficient for the total test was . 91 (corrected for length of the test).

and 35. Consistency of responses served to validate the scale. Inter viewers had been asked to rate subjectively the satisfactions that seemed to them to be most important to the respondents. This proved to be an unsatisfactory method of establishing validity as the interviewer's biases were such that almost all mothers were rated as attaching most importance to convenience. These ratings were not made according to a uniform understanding; therefore they are not reported.

The areas in which mothers reported highest satisfaction did appear to correspond to those needs donsidered of paramount importance to mothers in making child care arrangements. The satisfaction scale therefore seemed to be an appropriate beginning instrument to test the hypothesis of the study that satisfactions may be expected to be found in ordered patterns. The method described 
seemed to serve the purpose for which it was designed, i. e., to compare satisfaction with child care arrangements for divergent groups whose need for substitute child care was dictated by contrasting life circumstances.

In summary, the following limitations of the methods by which the study hypotheses were tested should be kept in mind.

(1) This was a preliminary attempt at measurement of relatively undeveloped content areas. The scale items were judged as discretely classified among the subscales, but the small number of items in each subscale necessarily limited the adequacy of any subscale to measure its domain. Some scale items were somewhat culture-bound or circumstance-bound for a sample group, thus limiting the items' effectiveness as a general criterion measure. The degree of reliability achieved for the scales was not high, since some items did not show an impressive ability to discriminate high and low satisfaction for the sample. With only moderate reliability, the results could not be definitive.

(2) An evaluation of the methods used would require crossvalidation before too much confidence should be placed in them. 
(3) The results were obtained on small samples of mothers subject to special conditions. It is not known what results might have been obtained for other, larger, more random1y selected samples. 


\section{CHAPTER III}

\section{FINDINGS}

\section{Introduction}

This chapter presents the findings regarding the association between economic necessity and satisfaction with child care arrangements. It describes the characteristics of the two groups and illustrates the impact that the life circumstances of the family has on the making of child care arrangements. Part A of this chapter summarizes and compares the content of the research interviews. In these interviews, certain economic and child care circumstances which constitute the predictor variables were identified. It was seen that the state of affluence alone plays an integral part in providing child care, although other factors such as family mobility, household conveniences, neighborhood resources, and presence of relatives also contribute some influence.

Part $B$ reports the findings of the testing of the hypotheses.

An appendix contains peripheral results in table form, such as ages, occupations, and other data which helped to determine the research conclusions. 
Part A: Comparison of Affluent and Low-income Families

\section{Household Composition}

There was a significant difference between the marital status of the Riverdale and Welfare mothers. As shown in Table V, every Riverdale mother was married and the husband lived in the home. In contrast, only nine of the Welfare mothers had husbands in the household. This was expected, however, because the Welfare mothers were chosen from the Aid to Dependent Children category; this assistance is based on the deprivation of children's financial support due to either continued absence, disability, or unemployment of a parent. Therefore the Welfare sample showed a higher incidence of families with the mother as the only parent.*

TABLE V

FAMILIES WITH HUSBANDS IN THE HOME

Riverdale

20

0
Welfare

Husband in Home

No Husband in Home

0

(1)
9

11

Although there was not a significant difference in the number

*From information received in the interview, Welfare assistance was given for the following reasons: continued absence of father (11) unemployment (6) and disability (3). 
of children in each of the groups, the study disclosed some interesting factors in family size and children's ages. The Riverdale parents were eight years older than the Welfare parents, on the average. Although the range in age of the children is similar between the Riverdale and Welfare samples, the distribution according to this age grouping differs markedly. (Figure 3)

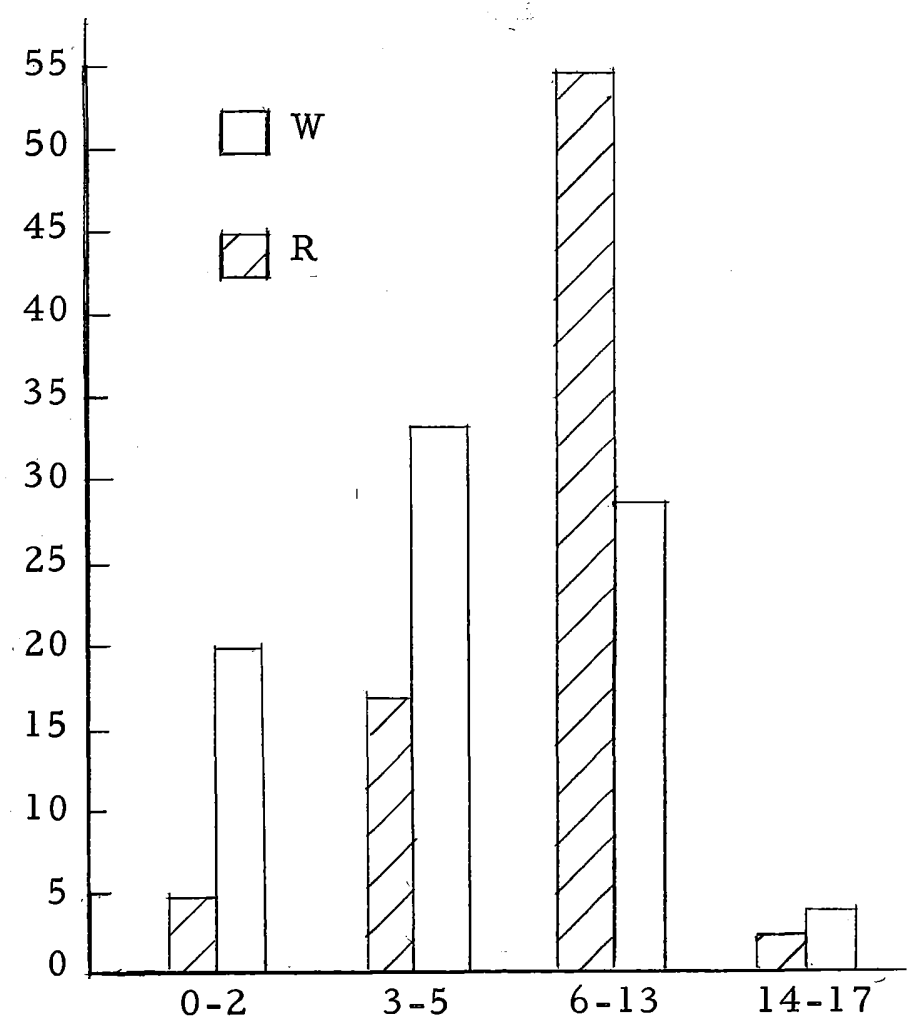

Figure 3. Distribution of Ages of Children

The preponderance of preschoolers in the Welfare families, in contrast to the few children of similar age in the Riverdale families, indicates that the child bearing role continues for the Welfare group while it may be virtually completed for Riverdale mothers. The number of preschool age children in the Welfare sample makes 
substitute child care a requisite for more Welfare families who need to be away from home than for their Riverdale counterparts. Because of the prevalence of preschoolers in the Welfare families, it can be concluded that they were currently more involved with many training aspects of the child care role than Riverdale mothers. All of these factors play an important part in child care arrangements needed and sought by the two groups, with an assumption that Riverdale families, at least during school hours, had less of a necessity for substitute child care.

Six of the Riverdale families had a non-related adult in the household. These persons were hired specifically to help with the housekeeping and child-caring chores. In addition, an adult relative in one Riverdale home served as the primary child-care resource. In contrast, no Welfare family had reported a non-related adult living in, but three of the families shared their homes with adult relatives. So even though Riverdale and Welfare families were essentially the same size, the need for child care due to preschool ages was greater within the Welfare group. However, these mothers had less help in the home, in terms of professional child care person or of husbands. *

*In the interviews, Welfare mothers represented husbands as child care help but Riverdale mothers generally did not, The schedule did not request this information and it is not known to what extent this help was recognized but taken for granted by the Riverdale mothers. 
Environmental Factors Contributing to Convenience

Much of the material relating to environmental factors contributing to convenience is given in table form in the appendix. However, some conclusions could be drawn concerning the comforts, advantages, and conveniences of the two groups. For example, the residential mobility of the families was to be examined. An assumption was that possibly the more residentially: stable families would be more knowledgeable of nearby. resources and, as a consequence, this knowledge could affect the child care decisions. The Riverdale families, perhaps because of their more advantageous financial circumstances, were able to make more lasting living plans. Table VI shows that 17 Riverdale families had lived in their homes over two years. In direct contrast, 17 of the Welfare families had lived at their present address less than two years. However, in contrast to expectations, Welfare families were more apt to find their child care resources within their community (i. e., neighbors and live-in TABLE VI

RESIDENCE AT CURRENT ADDRESS

\begin{tabular}{lcc} 
& Riverdale & Welfare \\
\hline Residence under 2 Years & 3 & 17 \\
Residence over 2 Years & 17 & 3 \\
\hline & Median length in household \\
& Riverdale: 3 l/2 - 4 years \\
& Welfare: & less than 1 year
\end{tabular}


relatives) than were Riverdale families, who search quite far to locate their at-home sitters.

Household conveniences were assessed as a factor in child care decisions. By making household tasks easier, more leisure time is created for the mother and, if she chooses, she can spend more time away from the home. Therefore, a check list of basic conveniences was prepared and a portion of it was devoted to recording spontaneous comments about conveniences. (Appendix I, Tables XXVI and XXVII) Although the two groups identified certain similar items as "'convenient", their interpretations often differed. As an example, characteristics classified as architecture of the home were listed as conveniences by families of both groups, but an entirely different visual picture emerges as this factor is defined. To a Riverdale family it might refer to the third floor laundry or the children's play room; a Welfare family saw this convenience in terms of the small home being easy to keep clean. Another example of differing definitions of the same item was play equipment; it was the swimming pool for a Riverdale family; for a Welfare family it was a Goodwill laundry basket commandeered by the children. Often the items volunteered as conveniences by the Riverdale mothers were expensive, such as an additional appliance, a housekeeper, or costly play equipment. Welfare families looked to less expensive resources for help, and for example, might list their relatives. 
It can thus be concluded that both groups identified convenience in their living circumstances, although their definition of this factor differed. How the convenience factors affected child care arrangements and satisfactions will be explored in Part B of this chapter.

Observations Regarding. Child Care Need and Child Care Arrangements

The survey showed that historically both groups of mothers evidenced considerable versatility in seeking child care arrangements (Appendix I, Table XXIX). The most used arrangement by the 20 mothers in the Riverdale sample was to have a sitter come into the home. By contrast, the most frequent child care resource for the Welfare mothers was found to be not their home, but the home of a relative. This difference is notable when compared with the response to the question about which of the child care arrangements the mothers found to be most satisfactory. All of the mothers of both groups stated a preference for a sitter to come to the home. Thus, what the Welfare mothers wanted and what they were able to get in a child care arrangement were two different things.

Nursery school experiences for children of Public Assistance families also fell short of desire. Most families in the Welfare 
sample expressed the wish that their children have this opportunity prior to entering grade school. However, because of lack of transportation, money, or facilities open to them, the Welfare children often went without nursery school experience.

TABLE VII

NURSERY SCHOOL EXPERIENCE

Riverdale 19
1
Welfare

6

Nursery School Experience

No Nursery School Experience
14

Data elicited about the current child care arrangement used by the two samples indicated that, again, the Riverdale mothers are able to obtain the kind of child care arrangement they desired, at least in the sense that the children are cared for at home. Appendix I, Table XXX lists the total range of current child care arrangements. Table VIII summarizes this data. It can be seen that all 20 of the

TABLE VIII

AT-HOME CHILD CARE ARRANGEMENTS

Riveredale 20

0

Welfare

Child Cared for at Home 12

Child Not Cared for at Home 8 
Riverdale mothers currently used at-home sitters, while only 12 of the Welfare mothers had this type of arrangement.

An indicant of child care necessity is the number of hours of child care needed per week. This study had a unique sample; the mothers were not primarily working mothers. Five Riverdale mothers were working, four worked part-time, and no Welfare mothers were employed. Consequently, it can be assumed that there would be a great deal of choice in terms of number of hours and times during which substitute child care was needed. Riverdale families needed substitute child care for considerably more hours than Welfare families. (Appendix I, Table XXXI) Also family demands and ability to pay for child care service contribute to the choice of arrangements made (Appendix I, Table XXXI) In essence, the Riverdale families, because of their smaller proportion of preschool children, had more freedom to get involved in away-fromhome activities. They also had the financial means to afford these activities, plus perhaps a greater knowledge of and interest in such non-home-maintenance activities as education and community activities. They committed themselves for regular involvement in many tasks and needed to employ a dependable sitter to be available for the 1 to 40 hours per week necessary. Under such circumstances, it can be surmised, they could not rely on less formal resources such as those neighbors and friends who 
served as a resource to Welfare mothers. Tables IX and X illustrate child care arrangement patterns which differ markedly between the two groups. It can be seen that Welfare families tended to locate their sitters on kinship and friendship lines while Riverdale mothers used the more forma: 1 , less intimate channels of agency referrals and babysitter lists provided by schools.

TABLE IX

HOW CURRENT ARRANGEMENTS LOCATED

\begin{tabular}{lcc}
\hline & Riverdale & Welfare \\
\hline Informal Channels & 11 & 20 \\
Formal Channels & 9 & 0 \\
\hline
\end{tabular}

TABLE X

WHO PROVIDES CARE IN CURRENT ARRANGEMENT

\begin{tabular}{lcc}
\hline & Riverdale & Welfare \\
\hline Provided by Relative & 4 & 11 \\
Provided by Non-Relative & 16 & 9 \\
\hline
\end{tabular}

In addition, there is an obvious factor of financial advantage. Extra money is not allocated in assistance grants to permit the mothers to pursue personal interests such as recreation, ADC clubs, or political action groups, but only for employment and training expenses and for a loosely. defined area called 
"self-improvement", for which all allowances can not exceed $\$ 10.00$ per month. Even assuming that the Welfare mothers had the time and inclination to be involved in away-from-home activities, it is apparent that only under limited circumstances could they afford them, or pay for the cost of substitute child care.

Considering the different types of axrangements being used by both groups, the Riverdale mothers paid more for their current arrangement. No Riverdale arrangement was "free". Fees paid ranged from $25 \%$ per hour to just under $\$ 300$ per month. In contrast, the Welfare group contained 16 families with child care service which was virtually free. *

\section{Conclusion}

The interviews revealed many similarities in the expectations and wishes for child care service, regardless of grouping. However, there are vast differences in the facilitating environmental factors that contribute both to child care need and child care resources found by the two groups.

From data presented in the text of this chapter plus tables included in the appendix, the following conclusions can be drawn about

*This item, ability to pay, was not clearly defined in the schedule, and was variously interpreted according to the circumstances of the mothers. For example, a Welfare mother could state she "could afford" the relativewho volunteers her child care services. 
the circumstances contributing to the wide latitude of choice found to be possible for the Riverdale mothers.

(1) Riverdale mothers, with a higher development of educational and employment skills, have a greater possibility of finding rewarding activities, including employment, outside of the home.

(2) Riverdale mothers take advantage of enrichment opportunities in the community, both for themselves and their children. They make more commitments to activities outside of the home for which they needed child care arrangements, a circumstance that would be different for samples of working mothers.

(3) Riverdale mothers have both husbands and live-in child care persons to help with the children.

(4) Riverdale mothers have more advantageous financial circumstances, largely due to their status of being married to men with considerable marketable employment skills.

(5) Riverdale mothers have lived in their homes for several years and they reap the advantages accruing to experience in a neighborhood.

(6) Riverdale mothers have more conveniences in terms of appliances and household help.

(7) Riverdale mothers can pay for the type of child care 
arrangements they want.

\section{Part B: Analysis and Discussion of Satisfaction Data}

The satisfaction scale consisted of 21 items which were scored on a seven point scale from strongly disagree to strongly agree. A score of five was representative of slight agreement with a positive item. The items in the scale measured satisfactions in four specific areas: convenience-dependability, money, relationship between mother and sitter, benefits to the child.

Tables XI, XII, XIII, and XIV show means and standard deviations on the scale and on each subscale for the Welfare and Riverdale groups of respondents. The difference between the means for the two groups was then tested by $t$ test, first for the satisfaction scale as an overall measure and then for the four subscales.

The satisfaction scale scores for the Welfare sample were not significantly different from the scores of the Riverdale sample; therefore the study rejected the hypothesis that the satisfaction with the child care arrangement in these two widely divergent samples would be associated inversely with economic necessity. The scores for the subscale related to convenience were not significantly different between the two groups at the 5\% level. This was also true of the subscale concerning benefits to the child.

The subscales of satisfaction with money and relationship 
TABLE XI

SATISFACTION WITH RELATIONSHIP TO SITTER

\begin{tabular}{lcccc}
\hline & Combined & Riverdale & Welfare & \\
Mean & Mean & Mean & \\
Item & Score & Score & Score & S.D. \\
\hline
\end{tabular}

6. My sitter and I sit and talk to each other for hours.

4.3

3. 0

5.7

2. 2

9. She takes an interest in me personally.

5.5

4.8

6.3

1.5

18. I get tired of her telling me her problems.

5. 3

5.3

5.3

1. 7

26. Sometimes she ignores my instructions.

4.6

5.0

4.3

1. 8

37. I feel she takes advantage of me.

5. 9

6.3

5.6

1. 3

43. She often takes time to sit down and talk.

5. 6

5. 1

6.2

0.5

Subscale Mean Score

5. 2

4. 9

5.5

Standard Deviation for the Entire Subscale $=1.7$

Coefficient of Reliability* $=0.55$ (corrected for length of test by Spearman-Brown Formula).

Difference between the two groups $=t=3.76 \quad P<.01$

*Split half (first half - second half). 
TABLE XII

SATISFACTION WITH THE BENEFITS TO THE CHILD

\begin{tabular}{lcccc}
\hline & Combined & Riverdale & Welfare & \\
Mean & Mean & Mean & \\
Item & Score & Score & Score & S. D. \\
\hline
\end{tabular}

5. She takes a real interest in my child.

6.4

6.7

6. 1

1. 4

12. My child picks up bad habits at the sitter's.

5. 4

5.6

5. 1

1.5

17. I like the way she keeps the children clean.
5. 9

5.6

6.2

1.2

21. My child learns some important things that he wouldn't learn at home by being with this sitter. 4 . 4. 5

4. 2

4. 8

1.5

24. My child is learning how to do things for him:self at the sitter's. 4. 7 3. 9 5.6 1. 7

39. I wish my sitter would spend more time doing things with my child. 4.4 4.5 4. 4 1.9

Subscale Mean Score

5.2

5.1 5.3

Standard Deviation for the Entire Subscale $=1.7$

Coefficient of Reliability $*=0.75$ (corrected for length of test by Spearman-Brown Formula)

Difference between the two groups $=t=1.38$ $\mathbf{P}<.10$ 
TABLE XIII

SATISFACTION WITH THE CONVENIENCE OF THE ARRANGEMENT

\begin{tabular}{lcccc}
\hline & Combined & Riverdale & Welfare & \\
Mean & Mean & Mean & \\
Item & Score & Score & Score & S. D. \\
\hline
\end{tabular}

14. Sitter lives too far away to be convenient.

5.2

5.2

5.3

1.3

16. I would be happier if I could depend on my sitter more.

5.2

5.6

4. 9

1.6

28. I can drop my child off at the sitter's anytime I need to.

4. 0

4. 0

4. 1

1.8

31. If I ever have to change my plans, she is very flexible about it. 5.4 5.7 5.1 1.4

41. I can count on my sitter to let me know if she plans to go anywhere out of the ordinary with my child.
6.0
6.2
5.8
1.2

42. She's someone you can count on in an emergency. 6.2 6.3

6.2 0.8

Subscale Mean Score 5.3

5.5

5.2

Standard Deviation for the Entire Subscale $=1.6$

Coefficient of Reliability $*=0.42$ (corrected for length of test by the Spearman-Brown Formula)

Difference between the two groups $=t=0.86 \quad P<.10$ 
TABLE XIV

SATISFACTION WITH THE MONEY PAID FOR SITTER

\begin{tabular}{lcccc}
\hline & Combined & Riverdale & Welfare & \\
Mean & Mean & Mean & \\
Item & Score & Score & Score & S. D. \\
\hline
\end{tabular}

8. I feel that I am paying

a reasonable fee for the care of my child.

$\begin{array}{llll}5.4 & 5.4 & 5.5 & 1.6\end{array}$

11. Most sitters want

more than I can pay.

4. 4

5.5

3. 4

2. 1

35. I think that sitters try to charge too much.

5.5

6. 1

4. 1

1.7

Subscale Mean Score

5.1

5.6

4.3

Standard Deviation for the Entire Subscale $=5.4$

Coefficient of Reliability $*=0.91$ (corrected for the length of test by Spearman-Brown Formula).

Difference between the two groups $=t=3.03 \quad \mathrm{P}<.01$

*Split half (first half - second half).

between mother and sitter were significantly different at the $5 \%$ level between the two groups. The Riverdale sample was more satisfied with the money component of its child care arrangements while the Welfare sample was more satisfied with the relationship of the mother to the sitter. Although there were these differences between the groups, the principal hypothesis was not accepted. In general, 
a higher level of satisfaction was not found among Riverdale mothers.

However, there was a difference in the patterns of satisfaction discovered within the groups. Guttman scale analysis was employed to analyze the patterns of the four subscale scores within each sample group. The scale scores for each mother were dichotomized as high or low using the same cutting points for both groups. "High" for a mother meant a mean score of five for the six items in each scale (three items for the money scale). Tables XV and XVI show that minimum standards of scalability* were found for the four subscales with the areas of satisfaction scaling in reverse order for the two groups.

How Should These Phenomena Be Interpreted?

The significant difference between the two groups regarding the satisfaction with the money involved in making child care

*Despite the small sample size, the coefficient of reproducibility for the subscales was at least .90 for each group (Guttman, 1950). The minimum marginal reproducibilities were acceptably low. For only one scale type did the number of non-scale types exceed the number of scale types. The relative frequency of scale types within each group approached statistical significance (Schuessler, 1961). Also, using a higher uniform cutting point, a comparable degree of scalability was achieved with a more balanced distribution of the frequencies of scale types (Rep. $=.90$ in both groups). 


\section{TABLE XV}

PATTERN OF SATISFACTION FOR THE WELFARE MOTHERS: A GUTTMAN SCALE

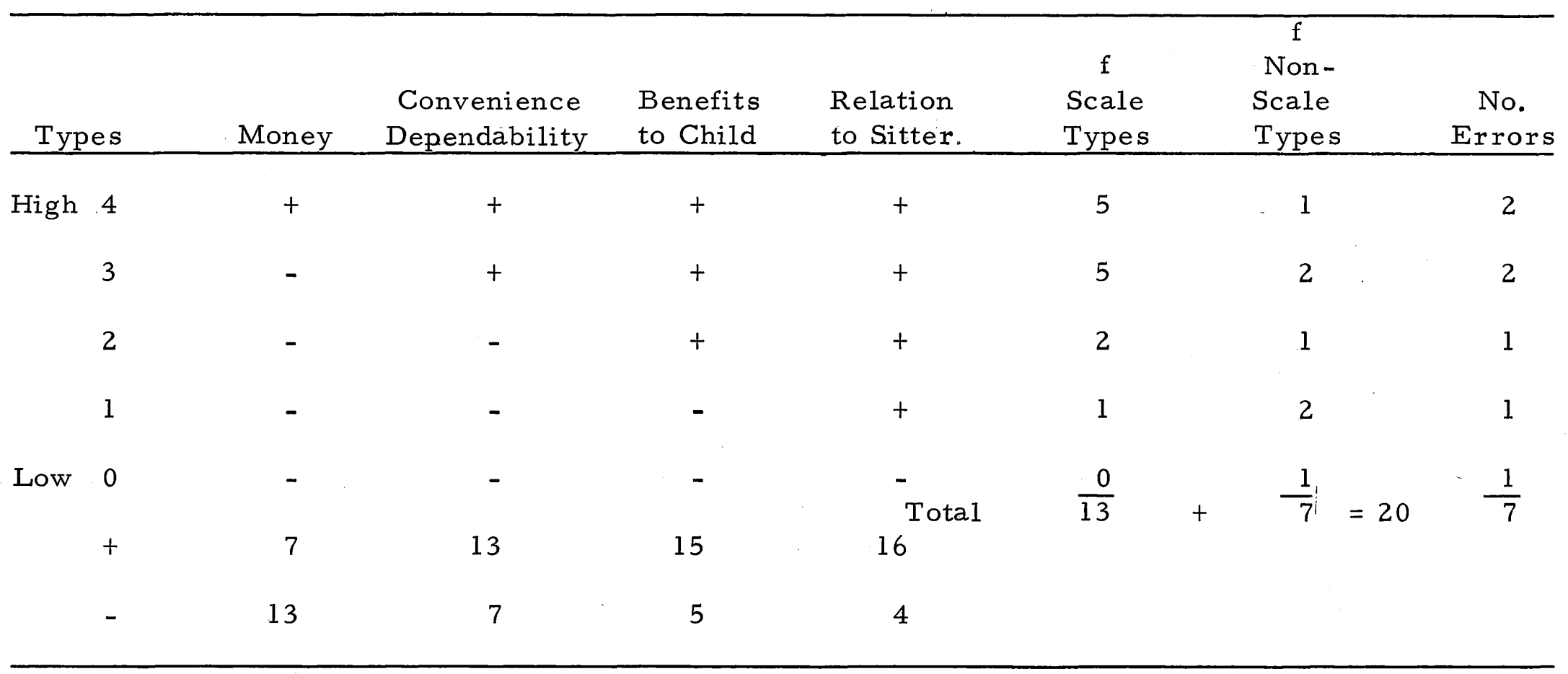

Reproducibility $=.91$

Minimum Marginal Reproducibility $=.71$

Observed frequency of Scale types $=13 ; \mathrm{z}=1.19 \% ; \mathrm{p}=.117$ 
TABLE XVI

PATTERN OF SATISFACTION FOR THE RIVERDALE MOTHERS: A GUTTMAN SCALE

\begin{tabular}{|c|c|c|c|c|c|c|c|c|c|c|}
\hline Type & & $\begin{array}{l}\text { Relation } \\
\text { to Sitter }\end{array}$ & $\begin{array}{c}\text { Benefits } \\
\text { to } \\
\text { Child } \\
\end{array}$ & $\begin{array}{c}\text { Convenience } \\
\text { Dependability }\end{array}$ & Money & $\begin{array}{c}\mathrm{f} \\
\text { Scale } \\
\text { Types }\end{array}$ & & $\begin{array}{c}\mathrm{f} \\
\text { Non- } \\
\text { Scale } \\
\text { Types } \\
\end{array}$ & & $\begin{array}{l}\text { No. } \\
\text { Errors }\end{array}$ \\
\hline \multirow[t]{4}{*}{ High } & 4 & + & + & + & + & 7 & & 2 & & 2 \\
\hline & 3 & - & + & + & + & 1 & & 1 & & 1 \\
\hline & 2 & - & - & + & + & 4 & & 1 & & 1 \\
\hline & 1 & - & - & - & + & 2 & & 1 & & 1 \\
\hline \multirow[t]{3}{*}{ Low } & 0 & - & - & - & Total & $\frac{1}{15}$ & + & $\frac{0}{5}$ & $=20$ & $\frac{0}{5}$ \\
\hline & + & 9 & 10 & 16 & 17 & & & & & \\
\hline & - & 11 & 10 & 4 & 3 & & & & & \\
\hline
\end{tabular}

Reproducibility $=.94$

Minimum Marginal Reproducibility $=.55$

Observed frequency of Scale types $=15 ; \mathrm{z}=1.29 * ; \mathrm{p}=.099$

*Corrected for continuity. 
arrangements could be explained by the fact that the Riverdale mothers, who were more satisfied, had the economic means to purchase what they wanted, and the Welfare sample did not. This would be borne out by the fact that the interviewers reported that the Riverdale sample felt that sitters charged high fees, and yet they scored as satisfied on the scale items. The Welfare sample, on the other hand, verbalized that sitters' fees were reasonable, and even less than what the work merited; however, they were unable to purchase this care because of limited finances. For this reason they may have scored significantly lower in their satisfaction with the money expended for their child care arrangements. The Riverdale sample satisfied themselves with the instrumental qualities of the arrangement first, according to the Guttman scale pattern, but they may have regarded the whole process of securing substitute child care as an instrumental process.

The Welfare sample scored higher on satisfaction with the mother-sitter relationship. The pattern of satisfaction responses for the Welfare mothers on the Guttman analysis shows a link between their satisfaction with the relationship to the sitter and what they perceived as beneficial for their child. It could be that the Welfare mothers saw arrangements in which they were satisfied with their personal relationship to the sitter as inherently good arrangements for their children. 
An alternate explanation of the difference between the satisfaction patterns of the two groups is that their scores scaled according to what expectations the mothers had regarding child care arrangements. The Riverdale mothers were interested in arrangements which were convenient and instrumental to their purposes for which child care was needed. Their relationships with the sitter were on a business basis. There was an absence of economic necessity for employment. Self-expression in employment and social activities did not provide the same pressure as the need to maintain the family through a mother's employment might have. The concept of benefits to the child may have been less tangible to these mothers because it is a less definitive, less salient a spect of an arrangement which can only be known through the testing of an arrangement through use. The Riverdale mothers did verbalize a concern that their children be well cared for when talking with the interviewers.

The Welfare sample expected to have good relationships with their neighbors, friends, and relatives whom they used as sitters. They were not away from the home for any great amount of time so that they used people with whom they already had formed relationships. If they had used regular child care arrangements to free them for employment, it is likely that they could not have relied so completely on these same types of arrangements. The Welfare sample utilized free child care whenever possible due to their 
limited financial resources. They did not expect the arrangement to be business-like in nature. Because of their relationship with the child care person, they saw them in a favorable light when as sessing them in regard to the benefits the child would receive.

By reviewing the results of the subscale tables of the two groups' mean scores on various items, more flesh can be added to the analysis.

Table XIV, Satisfaction with the Money Paid for Sitter, graphically depicts that the Riverdale sample scored high on these items, while the Welfare sample scored significantly less high $(\mathrm{p}<.01)$. The Riverdale mothers did not feel that the sitters wanted more than they could pay, but the Welfare mothers, feeling the paucity of their financial resources, did state they felt this way. Reflecting their financial circumstances again, the Riverdale group disagreed that sitters tried to charge too much, while the Welfare mothers slightly agreed with this statement. Irrespective of the other item answers and the interview data, both groups slightly agreed that they were paying a reasonable fee for child care, perhaps as a reflection of their current situation.

Convenience was an important factor in all arrangements according to what the mothers told the interviewers. Although the interviewers had become biased in their search to assess the meaning of convenience in a child care arrangement to mothers, 
nevertheless, they subjectively rated over $90 \%$ of the mothers as initially looking for arrangements which were convenient and dependable. Table XIII, Satisfaction with the Convenience of the Arrangement, has a subscale mean score of 5.3 on a 7 -point scale, which indicates that there is better than slight agreement with positively stated convenience items. Both groups had their highest agreement that the sitter was someone you could count on in an emergency. It is admitted that this particular item was invested with double meaning; however, it is unclear as to whether the respondents were agreeing that the sitter would care for the child if an emergency situation evolved which would necessitate substitute care immediately, or that she would be dependable in being able to handle emergency situations. The vague meaning of the item may be less confusing when associated with the remaining convenience items, which suggested a moderate degree of satisfaction with the flexibility and dependability of the sitter in responding to the mothers' child care needs.

An examination of the relationship subscale reveals a difference in the kinds of prevailing relationships between the mothers and sitters in the two groups, as well as difference in the levels of satisfactions reported. The following three items showed Welfare mothers better satisfied than the Riverdale mothers with expressive aspects of their relationship to the sitters. 
My sitter and I sit and talk to each other for hours.

She takes an interest in me personally.

She often takes time to sit down and talk.

On the other hand, the remaining three items on the relationship subscale showed that the Riverdale mothers approached being better satisfied. These items (all negative statements) were designed to tap possible dissatisfaction arising from lack of reciprocity in the relationship and feelings of being exploited.

I get tired of her telling me her problems. Sometimes she ignores my instructions. I feel she takes advantage of me.

It may be noted that Riverdale mothers did not feel taken advantage of by their sitters, being highly satisfied on these grounds, within the context of a less expressively, more instrumentally defined relationship to the sitter.

Both samples were satisfied with the benefits to their children of their arrangements. The Riverdale mothers registered slightly less agreement with items concerning skills that the child would acquire outside the home. It may be that this was so because the children were cared for primarily by persons from outside the family coming into the family home. The Riverdale mothers registered their highest agreement, which was close to strongly, agreeing, with the statement that the sitter took a real interest in her child. This item elicited a strong agreement response from the Welfare mothers 
also. The Welfare mothers agreed more strongly with the statement about liking the way in which the sitter kept their children clean. The Welfare mothers showed the lowest degree of satisfaction on an item expressing a wish that the sitter would spend more time doing things with their child. It could be because the Welfare mothers' arrangements were not paid for, and they did not feel that they could impose on the sitter by asking that she give the child more attention than she gave willingly. Since the Welfare mother perceived the sitter's behavior as good, usually, because of her relationship to her, the results of this item are unusual in the context of the study. Many Riverdale mothers also indicated on this item that they wished the sitter would pay more attention to their child. 
The hard reality of money as a facilitator for the purchasing of goods and services is significantly manifested throughout this study. Since the mothers of neither sample were driven by the pressures of full-time employment, a certain lack of desperateness to make child care arrangements was found among both groups of respondents. The Welfare mothers had no pressure to use sitters for specific time periods on a regular basis unless they happened to be working, and the Riverdale mothers had social schedules which were flexible to family situations unlike the daily necessity to appear on the job to earn the income for the family. A measure of the lack of desperation to make child care arrangements was the absence of any child care situation that appeared to be bordering on neglect.

\section{Child Care Necessity}

Parallel to the concept of economic necessity, the study developed a concept of child care necessity to refer to objective pressures arising from family composition and the need for substitute child care. The hypothesis was that child care necessity was negatively associated with satisfaction with the child care arrangement. Four indicants, equally weighted, were included in an index of child care necessity: 
(1) the number of children in the family

(2) the number of children under six in the family

(3) the number of hours of child care needed per week

(4) the number of resources for child care in the home. See Figure 1, page 4.

No association was found between the index of child care necessity and satisfaction with the child care arrangement, either for the total sample $(\mathrm{N}=40)$ or within the two socioeconomic subgroups of high and low economic necessity. Likewise, the predicted relationship was not found between satisfaction and any of the four indicants of child care necessity. (The tables showing these relationships are in Appendix J).

On the contrary, at least for the Riverdale mothers, a posi:tive association was approached between satisfaction with the arrangement and having children under six. Also contrary to expectation, mothers with live-in child care resources were not better satisfied with their arrangements.

Furthermore, an examination of the distribution of satisfaction scores by the number of hours per week mothers needed substitute child care appeared to suggest that the highly satisfied mothers were those who used substitute care the least or the most. See Appendix J.

Clearly, then, the objective characteristics of presumed child 
care necessity were not negatively as sociated with satisfaction with the arrangement made. In the light of these findings it does not seem reasonable to maintain that non-working mothers whose life circumstances are characterized by high child care necessity are less likely to make arrangements with which they will be satisfied. This study did not directly pay attention to the perceived or felt pressure of circumstances, but attempted to link satisfaction to objective conditions. The negative findings of the study, however, suggest the need to explore the intervening variables by which objective life circumstances may be associated with reports of satisfaction with child care arrangements.

\section{Summary}

Despite the small sample and the only partially successful measurement, the study supported the belief that mothers tend to make child care arrangements they regard as convenient. Indeed, the convenience of arrangements was a central concern for the mothers of both groups. The hypothesis that convenience ranks high in the hierarchy of values was not upset for the Riverdale group. However, the expected pattern of satisfactions was not found for Welfare mothers. The Welfare mothers were not significantly less satisfied with their arrangements, either with the convenience factors or with the benefits to the child. 
CHAPTER IV

FOUR CASE STUDIES

$\underline{\text { Introduction }}$

Case studies of four families were made to further our knowlege of the life styles and circumstances of the two different groups: Riverdale and Welfare. The objective of these studies was to further explore the effects of socioeconomic status on the life style and day care practices of these families. Oscar Lewis' use of the case study method in La Vida (1966) seemed appropriate to our study of child care arrangements of two different socioeconomic classes. Case studies, as he stated, have the ability to "get beyond form and structure to the realities of human life".

It was decided to adopt and simplify one technique from his model of case studies by conducting one taped interview with four mothers. They were requested to give their autobiography of the previous day in detail and to describe how it differed from other days, days when they used a sitter. Hoffman (1957) defends this method of case study by the following propositions:

(1) Recall of specific events and time are superior when describing the previous day in detail.

(2) Parent's behavior and handling of routine events is more 
or less consistent from day to day.

(3) The requirement made by the interviewer of the parent to recall specific events in the day tends to leave less chance for falsification of data as they are too busy reconstructing the day's events.

(4) The set to recall details seems to create a feeling of emotional isolation of the events taking place, thus letting the details reach consciousness without arousing anxieties which can make individuals repress or deny certain facts and feelings.

The four families to be studied were chosen after the interview schedules had been completed for each socioeconomic group. Two families with relatively high child care necessity and two families with low child care liabilities from each group were matched for the case studies. Child care necessity was indicated by the number of children in the household, amount of internal aid in child care within the family, and the number of hours the family needed child care.

The ability to verbalize as well as the interest of the mothers in further participation in the study was taken into account in selection of cases. After the initial interview consisting of the questionnaire and scale items, the interviewer noted on the schedule whether the mother was available and capable of further study.

The initial interviews of the Riverdale group were completed 
and two women were easily chosen. Mrs. Rivers, who stated she was interested in further study, had a husband and five children (two preschool age). She needed a sitter for approximately 29 hours a week for household duties, recreation, and volunteer community clubwork. It was felt that she met the qualifications of a high child care necessity family for Riverdale, due to the number of hours she spent out of the home, number of children, and lack of internal aid. in child care within her family. Her most used child care resource was "Dorothy", a student at Lewis and Clark College, and nursery school for her four-year-old boy.

The other Riverdale mother chosen, Mrs. Dale, had a husband and only one child ( $31 / 2$ years old) living in the home. She used a sitter 20 hours a week for activities such as: recreation, community work, education, and her beauty: shop appointment. Mrs. Dale was not currently employed, although she previously had worked 16 hours per week, as she was expecting a second child in two months. She had only one child and spent fewer hours out of the home than Mrs. Rivers. She normally used one of the Lewis and Clark college students (she had five students that might be used), a professional child care agency, as well as two different nursery schools that her daughter attended five mornings a week.

The two Riverdale mothers chosen were different in the number of children in their families, the number of hours spent outside 
the home, and the number of individuals and nursery schools caring for their children.

Difficulties arose in choosing two mothers to represent the Welfare sample for the case studies. Many did not want further involvement in the study. Of the three mothers who were chosen as under the least pressure of child care responsibility who were interested in participating, one had moved leaving no forwarding address, another had remarried and could not be located, and the third was mentally retarded. In the search for a Welfare mother who met the qualifications, a fourth possibility was discovered who had obtained full time work since the initial interview and was using the same sitter. Mrs. Wells, a divorcee, had three preschool children in the home and worked 40 hours a week as a waitress. Her sitter was a woman who lived in the same housing project only a few feet from Mrs. Wells' duplex.

Mrs. Phare was interested and available for further study. She had eight children in the home. Despite her many children (including two preschool age), her husband or her eldest daughter were available as free substitute child care. Her needs for a sitter were occasional--a maximum of five hours a week for household chores and recreation, though the children usually went with her for the latter.

These two Welfare mothers chosen for their high and low child 
care necessity had different number of hours that they spent out of the home, internal aid within the family for child care, and number of children within the family. Both mothers used regular sitters; one, a family member, the other, a neighbor.

The four mothers were chosen for case studies within their socioeconomic groups according to their child care necessities. After interviewing them, tabulation of satisfaction scores from the first interviews were completed. The two mothers who were ascertained to have high needs (Mrs. Rivers and Mrs. Wells) had higher satisfaction scores with their child care arrangements than the two mothers with low need (Mrs. Dale and Mrs. Phare). The total satisfaction scores with child care arrangements and the four sub-scale satisfaction scores between these four women, in relationship to the total sample of 40 mothers is pictured in Figure 4.

\section{Riverdale: High Child Care Necessity}

$\begin{array}{lll}\text { Family: } & \\ \text { Mo } & 32 \text { yr. } & \text { Son } 11 \text { yr. } \\ & & \text { Dau } 9 \text { yr. } \\ \text { Fa } & 36 \text { yr. } & \begin{array}{l}\text { Dau } 7 \text { yr. } \\ \text { Son } 4 \text { yr. }\end{array} \\ & & \text { Son } 9 \text { mos. }\end{array}$

Mrs. Rivers was an attractive brunette woman who wore slacks during the interview in her home. She had had two years of college and her husband, who was an owner of a business in Portland, had 


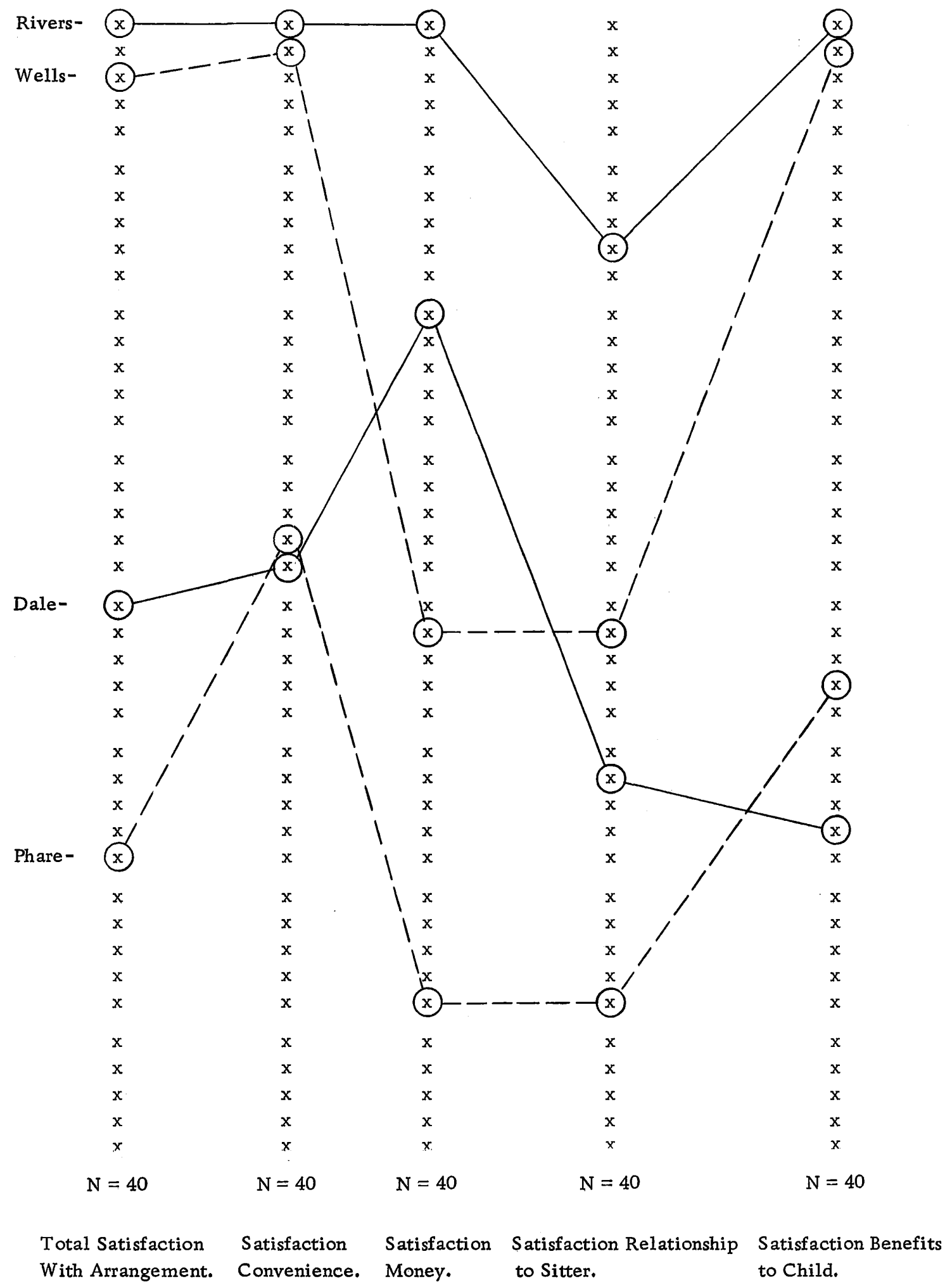

Figure 4. Relative Ranks of Case Study Mothers' Satisfaction With Arrangement. 
done graduate work in college. Her four year old son played quietly beside us in the family room. Mrs. Rivers was quick to respond and spoke freely of the difficulties of being a mother of five children and working approximately 12 hours per week for a volunteer organization. She was a woman of obvious organizational ability, and her warmth towards her preschool son characterized her congenial personality. She, her husband, and children had lived three years in a newly built spacious home designed for informal living for the family and the entertaining of guests. She had listed some of her conveniences as being: a washer, dryer, dishwasher, telephone, radio, TV, two cars, four bathrooms, garbage disposal, electric broom, and stereo. The design of her home seemed a convenience since it included bedrooms for all the children, except the baby, and an extremely practical day room that flowed into the breakfast nook and kitchen.

Yesterday:

Mrs. Rivers responded to the request to tell about the day before with a groan. She felt it had been an unusually hectic day. She had gotten up at about 6:30 a. m. The older son (11 years) woke the other children up and they got themselves washed, dressed, beds made and came upstairs, where she was making a large breakfast. The youngest daughter set the table. The entire family, with the 
exception of Mrs. Rivers and the baby, sat down to eat because the mother was too busy making lunches and tending to the baby $(9$ months).

After breakfast (approximately 7:45 a. m. ) the older boy fed the dog and went downstairs to finish getting ready for school and the two girls cleared the table while the oldest emptied the dishwasher.

As the father and grade school children were ready to leave, they all gathered to say a prayer together and departed. Mrs. Rivers then bathed and dressed the preschool boy and had him ready for his school bus at 9:00 a.m. After sending him off, she bathed the baby and put him down for a nap at 9:30 a.m. She was looking for ward to the usual quiet time after putting the baby down for his nap when the telephone rang. It was a woman from the volunteer organization telling her that the tape recorder and tapes that she and their group were to use to present a Christmas show for various children's homes had been stolen from their truck. The usually quiet morning was spent in telephoning the police, insurance companies, etc.

The preschool boy returned and she fed him lunch and then fed the baby. She made a casserole for dinner, then picked up the sitter at $l$ p. m. Leaving the sitter with the children, she drove to town to make arrangements to buy a new recorder, sign papers at the police, etc. She drove home at 3:00 p.m., picked up the three grade school children to take two of them to music lessons and one 
to the "Club" to swim. She continued looking at the library for music to record for the Christmas show. Unsuccessful in her efforts, she picked up the children from their various activities and returned home where the sitter had dinner ready. She took the sitter home, then returned to serve dinner, maintain order, and direct the dinner conversation. She and her husband were working on a new project of having the children in grade school read different posted articles from the newspaper before dinner to be discussed during the meal. Mrs. Rivers found it extremely difficult to organize this discussion along with meeting the usual needs of the children at the meal, but was successful and quite proud of herself. The children then cleared the table and went to their designated rooms to practice their lessons and do homework. She then put the baby to bed first, followed by the preschool boy. After this, she helped the older boy with his French lessons, and told the younger girls to go to bed. The older boy put himself to bed and read as long as he wanted to read. His lights were out at 9:30 p. m. Her husband returned home from his meeting and she told him of the difficulties of the day. She did not feel there was a relaxing moment until she got to bed.

Mrs. Rivers stated that the difference between yesterday and the usual was that she did not have her morning free to relax and do her washing or housework, and her husband was not home for dinner 
to provide structure and control over the children's behavior at the table. Mrs. Rivers stated she relied on her husband for emotional support as well as providing the ultimate control over her children and without him sometimes felt overwhelmed. When she has been ill her husband takes over the morning chores of breakfast, and caring for the children, as well as the evening meal.

Her most used sitter and the sitter of "yesterday" was "Dorothy", a Lewis and Clark student. She likes this sitter because she is "motherly", a good cook, controls the children, and can carry through with instructions and the care of the children. She pays her $\$ 1.00$ per hour and has used her for one year.

Previous to this sitter she used a cleaning lady for whom she still feels a great deal of affection. They worked together in sort of a team effort in cleaning and caring for the children. Unfortunately, this woman has been too ill to work though Mrs. Rivers has called her to ask if she could not just come to watch the children while she did the heavy cleaning. Her husband objected to paying her her usual wage of $\$ 1.50$ per hour for this, but Mrs. Rivers would have simply liked to have her back again. The cleaning lady that she had during the initial interview had quit between interviews and had not been dependable. 


\section{Welfare: High Child Care Necessity}

Family:

Mo 28 yr. Dau 5 yr.

Dau 4 yr.

Son $21 / 2$ yr.

Mrs. Wells, with her short reddish hair and plump figure had a vibrant personality and spoke rapidly. She seemed extremely nervous and flighty. Arrangements for this interview were made before dinner a few days prior when Mrs. Wells, surrounded by screaming children (the neighbor's and her own) and barking dogs, stated she would like to talk about her family and herself to get her mind away from her boy friend, who had just left her. She seemed especially concerned because she had been committed to Holladay Park Hospital when her husband left her a few years previously. A time for the interview was set, when she was not working and the children would be in bed.

Mrs. Wells had completed high school and was recently employed as a waitress though she was still receiving Welfare aid because she was not earning enough to support her family. She and her family, were living in a housing project for lower income families. She listed as her conveniences: a radio, $\mathrm{TV}_{9}$ one bathroom, and the wash house, including a washer and dryer provided by the housing project.

The three children, sleeping in one room, were in their beds 
adjacent to the living, room during the taped interview Sunday evening. All were asleep except for the older daughter who added statements such as: "Remember about the time you threw the hammer through the window?" and "Tell her about dumping the milk over my head at dinner tonight". Each comment was followed by a giggle from both of them and Mrs. Wells elaborated on the incidents.

Yesterday:

Mrs. Wells worked that day (Saturday). She woke the children at 8 a.m., dressed them and got them ready for the day at the sitter's since none of them had school. It included getting their warmer jackets and finding various toys that they wanted with them; stuffed animals for each and a truck for her son.

Around 8:30 a.m. she walked with them over to the sitter's where the children ate breakfast. This day she just greeted the sitter at the door and left for her neighbor's house where she ate her breakfast. She felt that the nicest time of the whole day was the half hour breakfast she spent with her friend across the court with no children around and no work. They discussed their mutual problems with children and men.

Around 9:45 a.m. she left, and walked to the restaurant where she works. She returned from work at 6 p. m., picked up the children, and returned home with them to make dinner. She 
described this time as being the most hectic. Both she and the children were tired and hungry and her children wanted constant attention from her. They hung on her skirt while she made dinner, fought with each other, and watched TV. She served them a meal having all of them sit down at once (a new program she is attempt. ing). When all of them were sitting and eating at the table they started giggling and the older one did not want to drink her milk. Mrs. Wells became frustrated with her and dumped the milk over her head. She related that they all felt this was a big joke and laughed about it.

After dinner she cleaned up the kitchen while the children were watching TV. Later, she joined them and about 8 p. m. told the two younger ones to go to bed. She hoped they would be asleep in a half hour when the older girl went to bed but they were not. It was around $9:$ p.m. when they were all asleep and she went to bed.

This day, as described by Mrs. Wells, was different from others because the two girls did not have nursery school since it was Saturday. When they did, she had them eat breakfast at home rather than at the sitter's and they left from home to go to school. Another unusual event was that she did not go out that evening with her boy friend, as she had broken up with him. When she did go out with him, he paid for the sitter. After eating dinner with the 
children, she took them back to the sitter with their bed clothes and stuffed animals, or in some cases they just stayed at the sitter's for dinner. The sitter kept the children overnight so they did not interfere with her having her boy, friend spend the night with her or her staying out late. She picked the children up by $8 \mathrm{a} . \mathrm{m}$. the following morning after they had eaten their breakfast in the sitter's home.

Although it is against the housing rules to have men stay overnight, she felt you only got into trouble if someone "had a grudge against you" and reported you. One of the ways to accumulate a grudge was asking someone to watch your children as a "favor". Favors were expected to be returned and often a mother called just as she was ready to leave on a date, and expected her to care for her children. If she did not sit, they became angry. Mrs. Wells found the most important thing was to be able to pay for a sitter which leaves no other obligations. With the help of Welfare she is able to pay her sitter $\$ 25.00$ per week plus $\$ 15.00$ worth of food stamps while she is working. If it were on the hourly basis for the evenings, she paid $35 \dot{\xi}$ per hour.

The sitter seemed to be always available. If the sitter was busy, her husband or son took care of the children. Mrs. Wells respects the sitter's ability to care for her children and leaves no instructions. In fact, the sitter instructs Mrs. Wells concerning the children's behavior, illnesses and how to handle them. 
She felt that the sitter overstepped her boundaries when she advised her about men and how to handle her personal affairs, but she felt that the sitter knew more about caring for children than she did.

The freedom of having more money, as well as being away from the children were the two major reasons she like being back at work. She stated a need for the security of Welfare supplementation of her check, free medical care, food stamps, and payment for the sitter. These benefits aided her in being able to obtain a sitter and freeing her to work and to pursue her own personal interests and needs.

Riverdale: Low Child Care Necessity

Family:

Mo 27 yr. Dau $31 / 2 \mathrm{yr}$. Fa 34 yr.

Mrs. Dale was an attractive light-brown haired woman of 27 years who had completed two years of college and worked part time as an interior designer. Her husband had completed four years of college and was a stock broker. Mrs. Dale was expecting her second child in two months. She felt she had few problems in obtaining care for her child presently since she was now attending nursery school five mornings a week and could stay with the neighbors now that she was more self-sufficient. The daughter was with us in the 
living room during the interview, eating a sandwich.

Mrs. Dale seemed to be extremely self-conscious during the . interview though she had stated an interest in further study. This anxiety seemed to have been increased by the tape recorder and the inexperience of the interviewer in this method of interviewing and clarifying specifically the expectations of verbalizing yesterday's activities. Hence, the information pertaining to the entire day's activities was incomplete. After the recorder was turned off Mrs. Dale became more relaxed and related more information concerning some of the difficulties she was having and expecting to have after the birth of her second child.

Mrs. Dale lives in an older formal home situated just below the Lewis and Clark College campus. They have lived there for three years. She listed as her conveniences: a washer, dryer, two telephones, radio, two TV sets, two cars, three bathrooms, and a cleaning woman that comes once a week.

Yesterday:

Mrs. Dale described the day as very unusual since she had to pick up her husband at the train station at $5 \mathrm{a} . \mathrm{m}$. She woke up at 4:30 a. m. and got herself and her daughter dressed. Hurriedly, they drove to the station to meet her husband. After meeting him, they ate breakfast together downtown and returned home. She 
retired to bed while her husband played with their child until the cleaning lady arrived. He then left for work. The cleaning lady watched the child until it was time to send her to school and a member of the car pool called for her. The girl returned home for lunch which Mrs. Dale fixed.

Mrs. Dale described dinner time as the most difficult time of the day. She began dinner a round 6:30 p.m. about the time her husband returned from work. She talked with him in the kitchen while making dinner and her daughter ran back and forth between the TV set in the living room and the kitchen. She found this very dis tracting since she wanted to talk to her husband and her child was demanding his attention. She sent her back to the living room repeatedly.

When dinner was ready, they all sat down at the table and her daughter, who had been refusing to eat dinner lately, refused to eat, so this night she put her to bed. She and her husband finished dinner together in peace and quiet.

This day was not typical with reference to her usual days since Mrs. Dale and her child usually got up after her husband had left for work. They then went downstairs in their robes and slippers and ate breakfast together. After breakfast she got her ready for school and either took her turn in the car pool or sent her out the 
door for the other drivers to take to school.

It was also atypical in that her daughter was going through a difficult period in eating dinner. Usually, she finished and retired to the TV set or her father played with her while the mother cleaned the kitchen and did the dishes. She then put her pajamas on her and sometimes read to her for a few minutes while she was in bed.

Mrs. Dale felt that her quietest and most relaxing time of the day was during the mornings when her daughter attended nursery school. Afternoons were often a problem because she could not always get a sitter, but had to plan ahead and call a day in advance at the professional child care agency or take her chances that a Lewis and Clark girl would be free. She was planning on leaving her daughter at a neighbor's house to play the afternoon of this interview. She felt she was old enough not to be a bother to a neighbor to watch her now that she was $31 / 2$ years old.

Mrs. Dale preferred students as sitters because they could better entertain the child, and she thought they were quicker to handle emergency situations. However, she did not find them always available when she needed them. The professional child care agency was more dependable and would replace a woman if one was unable to come, but not only did she have to plan ahead and contact them a day in advance but she felt that they charged too much money. The college girls charged $50 \&$ per hour and the agency women $\$ 1.00$ 
per hour.

Mrs. Dale was not looking forward to the axrival of her new baby in that she would have more difficulties in finding a sitter. She felt that she would have to plan ahead and use an agency sitter. She was planning to have a live-in nurse for the first two months after the child was born, but after this, she would probably use an agency sitter.

\section{Welfare: Low Child Care Necessity}

$\begin{array}{ll}\text { Family: } & \\ \text { Mo } 42 \text { yr. } & \text { Dau } 16 \text { yr. } \\ \text { Fa } 45 \text { yr. } & \text { Dau } 14 \text { yr. } \\ & \text { Dau } 13 \text { yr. } \\ & \text { Dau } 12 \text { yr. } \\ & \text { Dau } 11 \text { yr. } \\ & \text { Dau } 9 \text { yr. } \\ & \text { Dau } 3 \text { yr. } \\ & \text { Son } 2 \text { yr. }\end{array}$

Mrs. Phare, a mother of eight children, was a dark-haired stocky woman of 42 years. She wore blue jeans, boots and a blouse during the interview in her home. She was quite articulate in describing the previous day's events and her concerns about her children and herself. She had obtained a college degree and had worked as an insurance investigator for a firm in Portland. Her husband, whom she rarely mentioned in the interview, unless prompted by the interviewer, had been disabled since 1963 due to a bone disease. He had completed one year of college and previous to his illness had 
done manual labor. Mrs. Phare stated the problem she had had with baby sitters was her primary reason for staying home and not working currently. She felt that her children had not gotten enough attention and affection from the various sitters she had used while she was working. However, she was considering going back to work sometime in the future.

The home, situated in a built-up residential area, was old but the one room in which the interview was held was very tastefully decorated by Mr. and Mrs. Phare. She, with the help of her husband, had put in wood panels on the walls, a metal modern fireplace, and curtains. The early American furniture was in various states of repair. This room was like a family room and was next to the kitchen and utility room. Mrs. Phare had listed her conveniences as: washer, dryer, TV, one car, and two bathrooms.

The two preschool children awoke during the interview. The three year old girl went back upstairs and the two year old boy stayed with the mother who rocked him in her chair during the remainder of the interview.

Yesterday:

The previous day, Mrs. Phare had been awakened by her radio alarm clock about 6:30 a.m. She woke up all the children except the two preschool children. The girls got dressed, made their own 
breakfast and when they were ready, she drove them all to their schools.

Upon returning she tried to get a few things done such as dishes and cleaning. The two preschool children woke up at 10 a. m. and after dressing and feeding them, she swept and mopped the kitchen floor. Her daughter, who is three years old, wanted to help mop the floor. With Mrs. Phare's aid she mopped the floor and the mother wrang out the mop for her. The girl wanted to clean the shelves in the family room and Mrs. Phare told her it was all right and went upstairs to do some cleaning. She came back to find the shelves spotless and all the books on the floor. It took her almost ten minutes to put them all back and clean up the mess.

Her 11 year old daughter came home for lunch from her grade school, which is nearby, bringing a friend with her. Mrs. Phare made a meal of soup, sandwiches and fruit for the two girls, the two younger children, and herself. They sat around and talked until the girls had to go back to school. After they left, Mrs. Phare did the dishes and then washed some clothes. This was a quiet time, for she had put the two younger children upstairs for a nap.

The school aged children started coming home a round $3: 30$ p. m. Three of the grade school children stayed at school to swim, but the oldest high school girl had to interview a woman at the Oregonian Building at 4 p.m. Mrs. Phare took the two high school 
girls downtown and brought them back after the interview. The nine year old was by herself watching TV when they returned; the two younger children were upstairs with their father. She had dinner ready at 6 p. m. After the meal the girls sat in the dining room doing their homework. The younger ones without school work watched TV. Mrs. Phare helped each girl with her homework as they all wanted her help. She felt they were actually just asking for her attention but they were also having problems with their academic work. Her husband wanted her to sit and watch TV with him and not help the children. This she felt was the most difficult time of the day with all the older girls and her husband wanting her attention.

After their homework was completed they went to bed individually or in pairs without any direction from her. They all took baths before bed as they like playing in the tub. The last one to bed was around $11 \mathrm{p} . \mathrm{m}$. and the younger two were among the last of the children upstairs. She corrected the older daughter's work at 11 p. m. while the girl did the dishes.

With all the children (and apparently her husband) in bed, Mrs. Phare stayed downstairs by herself reading a Reader's Digest condensed story until around 1:30 or $2 \mathrm{a} . \mathrm{m}$. She relished this time for it was the only period in which she was by herself and could think and read. She felt she paid for this late hour as usual for she woke up groggy and tired the following morning. 
Mrs. Phare felt that the previous day was fairly typical of her family's daily life, except that she often does not wake the girls for she is too tired in the morning. One of the older girls wakes the others and after they get their breakfast, they wake her in time to take them to school.

The last time this mother used a sitter was the past weekend when she and her husband went to visit relatives in the evening. The older girl was in charge though the other teenage girls would not take directions from her. She is good, however, with the two little children. Mrs. Phare feels the girls do not like her because she becomes too bossy. The girls do not get paid for sitting and often feel imposed upon. It seems that Mrs. Phare often sacrifices her own activities and interests to keep peace with her daughters. If there is too much conflict and she has to go somewhere, she often takes them all with her.

\section{Conclusion}

This study involved four families who were chosen for case studies to further investigate the effect of socioeconomic status on family functioning and child care practices. The method used to study these families was one taped interview, in which the mother was asked to describe in detail the previous day's activities, how it 
differed from more normal days, and days when she used a sitter. Two families with high and low child care necessity were matched for these studies from both socioeconomic groups: Riverdale and Welfare.

This method of studying families was found to have the advantage of being economical in time requirements of the interviewer, yet at the same time, produced some detailed description of the family's way of functioning and use of child care arrangements. The relatively unstructuredness of this approach, as opposed to the in-... terview schedule, gave a fuller picture of how the individual families functioned and the different uses and problems of day care arrangements. The disadvantage of this approach to case studies was that it required a mother to have high motivation and capacity to verbalize. Therefore, these women were not necessarily representative of the total sample of 40 women nor of their own socioeconomic group, although their satisfaction scale scores ranked from 1 to 30 .

The two Welfare mothers (Mrs. Wells and Mrs. Phare) also not representative of their socioeconomic group because of present and past circumstances. Mrs. Wells was the only mother in the sample receiving regula $x$ payments from an agency that enabled her to have a regular sitter. Mrs. Phare was the one mother in the Welfare group who was a college graduate. This might suggest a different social orientation to her family and babysitting. 
The information from the case studies suggested reasons why the women responded to the satisfaction items with different degrees of agreement and disagreement. It also suggested that the items had different meaning to the four mothers. Two items in the convenience subscale evoked different responses because of the mother's personal situations:

28. I can drop my child off at the sitter's anytime I need to. mother: Mrs. Rivers Mrs. Dale Mrs. Wells Mrs. Phare $\begin{array}{ccccc} & 6 & 2 & 7 & 2 \\ \text { scores: } & \text { agree } & \text { disagree } & \text { strongly } & \text { disagree }\end{array}$ agree

31. If I ever have to change my plans, she is very flexible about it.

mother: Mrs. Rivers Mrs. Dale Mrs. Wells Mrs. Phare

$\begin{array}{cccc}7 & 6 & 6 & 5 \\ \text { strongly } & \text { agree } & \text { agree } & \text { slightly } \\ \text { agree } & & & \text { agree }\end{array}$

Although only one woman used a sitter out of her home, they seemed to all react to \#28 according to their circumstances. The mothers with high child care necessity (Mrs. Rivers and Mrs. Wells) were satisfied with the availability of their arrangement while the mothers with low child care necessity (Mrs. Dale and Mrs. Phare) were dissatisfied. One of the major factors in determining high and low child care necessity within the groups was the number of hours a child care arrangement was needed. This item indicated the reason why the mothers with low child care necessity had a 
smaller number of hours out of the home. They could not find an available sitter when they needed one.

Mrs. Rivers who used her sitter 29 hours per week and had a large number of children needing a sitter, found "Dorothy" available almost all the time in the afternoons and evenings. However, she did have morning classes, but with this limitation, Mrs. Rivers scored a high satisfaction on this item. Mrs. Dale (low child care necessity) was not as fortunate to find her sitters as available, though she had a number of possible resources. If she planned a day in advance, a professional agency would provide a babysitter. She stated concern for this problem as sometimes she was unable to obtain a sitter on short notice.

Mrs. Wells (high child care necessity) used a sitter who seemed to be available both night and day without prior notice; she scored high in satisfaction on this item. If the sitter was not home, the husband or son would care for her children. However, Mrs. Phare (low child care necessity) hesitated to use her daughter frequently or without prior notice because her daughter felt imposed upon and often had other plans. Thus, she was less satisfied with this item and unable to spend more hours away from home.

All four mothers were relatively satisfied with item \#31. It seemed that Mrs. Dale and Mrs. Phare were saying that after the arrangement was made and the sitter was caring for their children, 
they would stay longer if need be, rather than being available on short notice. Mrs. Phare still had a lower satisfaction score, which again seemed to suggest the resentment that her daughter has toward sitting. All mothers felt then, that once the sitter was contacted they were flexible in the time spent caring for their children.

Convenience for these women was of primary importance. They tended to make the most convenient arrangement that they could within their individual circumstances. However, the most satisfied women with their arrangements, Mrs. Rivers and Mrs. Wells, both having high child care necessity, had arrangements that were more available when they wanted them. Mrs. Dale and Mrs. Phare described this area as having a great amount of dissatisfaction for them in the case studies. Mrs. Dale had to plan in advance for a sitter and was not always successful. Mrs. Phare felt it caused a great amount of strain for herself because of the resentment that her daughter had toward sitting. Therefore, she rarely: went out without taking the children with her.

It would seem that the convenience questions did not measure this area well. The one statement \#28 was closest to this area of concern and importance but could have been worded differently to fit their circumstances, as few mothers had sitters outside the home. The case studies also reflected why the pattern of responses of the four mothers were different in the Guttman scale. All four 
women had different patterns within their socioeconomic groups. Mrs. Rivers fell within the Riverdale group that was most satisfied with the four subscales. She liked her sitter personally and seemed to identify with her as a peer since she had gone to college too. She also like the way this sitter related to the children and was able to control and "mother" them. Mrs. Rivers maneuvered her schedule around the limitations of her sitter's morning classes. The sitter was available at the times that Mrs. Rivers needed her in the afternoons and evenings.

However, Mrs. Dale whose pattern of satisfaction conformed to the Scalar pattern, scored high satisfaction in money and convenience, but not in relationship to sitter or benefits to child. She fell in the middle scale type of the Riverdale mothers on the Guttman scale. Her low satisfaction with benefits to child is possibly a reflection of her feelings of rejection toward her daughter. She has made arrangements so that her child is away from the home five mornings a week, and she uses many different sitters for the afternoons and evenings. If one is not available she uses another. This did not seem to be in relationship to her personal feelings toward her sitter nor how well the child likes the sitter. Mrs. Dale does have a supply of sitters who are available within one day's notice and has the money to pay them. It is interesting to note that in the interview she felt sitters were paid too much money but did not respond this 
way on the card items.

Within the Welfare group,Mrs. Wells' satisfaction scores on all subscales fell within the group that was most satisfied with all aspects of the arrangement. Mrs. Wells had an extremely available sitter, was receiving aid to pay for the sitter either by an agency or previously, by her boy friend. The sitter lives across the court from her home and is within walking distance. Mrs. Wells felt that the sitter knew more about caring for the children than she did herself, and she seemed to use her sitter as an alter-mother. They were both in the same socioeconomic class and their relationship was considerably different than the one Mrs. Dale had with her sitters.

Mrs. Phare's satisfaction scores were atypical for the Welfare group. She had high satisfaction with the convenience and benefits to the child, but low in the relationship to the sitter and the money items. This seemed to be reflected in her case study as she described the problems of using her daughter as the sitter. As Mrs. Phare had no money to pay her or another sitter, this was quite a problem and her daughter resented being used. The mother seemed to have little control over the situation and chose to stay home or take all the children if the daughter refused to sit. However, she felt it was better for her children to have a member of the family care for them, as she thought the different babysitters she had used 
while she had been working had been detrimental to her children. Because of this she scored high in benefits to the child.

In conclusion, then, the case studies helped to describe what the different mothers were reacting to in responding to the satis faction items. The satisfaction scores of these four mothers seemed to reflect an interaction between the mothers' personal needs and their life circumstances, which, together, determined the options for child care that they selected. All mothers stated a desire to pursue interests outside the household which required the use of substitute child care. The relative unstructured case study approach gave a fuller picture of how the individual families functioned and of the different uses and problems of day care arrangements. 


\section{CHAPTER V}

\section{CONCLUSIONS}

The purpose of this chapter is to present further discussion of the findings, interpretations of the findings, and implications for further studies.

\section{Summary of Study}

This project was a study of mothers' attitudes toward child care arrangements. It was hypothesized that the satisfaction with child care arrangements would be associated inversely with eco:nomic necessity and child care necessity.

Economic nacessity referred to the socioeconomic level, the criterion being belonging to an affluent group of society or to a poverty level group. Child care necessity referred to the number of children for whom substitute child care was needed, in relation to the child care resources of the family.

The underlying as sumptions were that life circumstances determine attitudes and that satisfaction would reflect the life circumstances. It was thought that the mothers' life circumstances would partially determine their ability to make child care arrangements with which they would be satisfied.

It was reasoned that the affluent group would be better 
satisfied with their child care arrangements because their circumstances would allow a wide choice of arrangements that met their criteria for child care. It was thought the poverty level group would be less satisfied.

In making child care arrangements it was also assumed that the convenience of the arrangement would have prior importance to the mother over the benefits to the child. It was felt this latter value assumed importance only after the need for a convenient arrangement is met.

A sample of 40 was selected; 20 each in an affluent and in a poverty level group. The mothers were interviewed according to a predesigned questionnaire, and a card sort with a seven point scale was administered, using items designed in the areas of conveniencedependability, benefits to the child, mother-sitter relationship, and fees for child care.

Case study interviews were held with four sample families chosen after the initial interviews. The purpose was to further investigate the effect of socioeconomic status on family functioning, attitudes, and child care arrangements.

\section{$\underline{\text { Results and Conclusions }}$}

The hypothesis that higher satisfaction would be found among the Riverdale mothers was not confirmed. The affluent mothers 
were significantly better satisfied with the general financial cost of arrangements and significantly less well satisfied with their relationship to the sitter. However, there was no difference in the two key scale scores, those of convenience and the benefits to the child.

The results were generally consistent with the basic assumption that satisfaction reflects basic economic and child care circumstances but not in the direct way anticipated. Predictably, satisfaction with the financial aspects of arrangements was associated negatively with economic necessity. But, the affluent mothers, for all their economic and social advantages that facilitate the making of arrangements were not significantly better satisfied with the convenience of their arrangements, nor with the benefits they perceived their arrangements had for their children,

A possible interpretation of the lack of differences in the convenience scale scores may, be that the two groups did not have the same need for convenience. It seems reasonable to interpret this in the light of the fact that the poverty level mothers were not involved in as many activities outside of their homes for which they would require child care arrangements. The affluent mothers had social pressures, status pressures, group values, and personal needs to be involved in activities outside of the home though not employed. Convenience was more important to them.

If the Welfare mothers had been involved in as many activities 
or had been working and had had to make child care arrangements, it is likely the pressure on them to make convenient arrangements would have been greater. It may also be that for the poverty level mothers, with a lack of income, transportation and social commitment, any type of arrangement that released them from their limited life circumstances is seen as convenient. Therefore, more satisfaction would be reflected.

Although the satisfaction levels reported by the two groups were similar, the satisfaction patterns did differ. The pattern for the affluent group was consistent with the hypothesis that the mothers' needs must be met first in her satisfaction with a child care arrangement, benefits to the child coming after the convenience of an arrangement was satisfactorily met. It would seem logical that the poverty level mothers with their lack of resources would be concerned primarily with convenience. However, the affluent mothers, with vast resources available still were most interested in conveni ence.

This implies that the mothers' personal needs for convenience takes priority regardless of socioeconomic standing. Perhaps the poverty level mothers, given all the advantages of the affluent group, still would consider convenience first.

There was a significant difference between the groups regarding some of the money scale items. Both groups of mothers slightly 
agreed that they were paying a reasonable fee, but the poverty group felt that the fees were higher than they could afford to pay. In their interviews and comments the mothers appeared to be reacting to what they could pay, not to what they wanted to pay. The affluent group did feel fees were high although they could pay them. The poverty level group appeared to feel that fees were reasonable and even low, but could not afford to pay them.

A possible interpretation might be that many of the affluent mothers spent a great deal of time away from home. Most have either mother's helpers, a housekeeper, cleaning woman and/or live-in sitters, and two nursery schools readily available. It could indicate that the affluent mothers had less exclusive responsibility for care and housework, and may have been less keenly aware of the responsibility and physical work which goes into running a home and family by one's own labor.

There was a significant difference between the groups in the degree of their satisfaction with relationship to the sitter. The affluent mother did not attach much importance to the expressive or intrinsic values of the relationship; the poverty level mother at tached great importance to her personal relationship to the sitter. The affluent mothers seemed to want a professional relationship; the sitter provided services and was reimbursed accordingly. It seems plausible to interpret this in the light of the fact that 
for Welfare clients poverty does not end with finances. (Herzog, 1968). They must live in areas where inexpensive housing is available. They are quite mobile, therefore limiting the possibility that enduring relationships would form in the community or neighborhood. This combined with the financial difficulty in not being able to leave their children to go out, adds to the importance of relationship with others.

The poverty level mother had to rely on her own social clas and family for sitters. It is culturally a peer group relationship and as such the setting is more appropriate for a personal relationship to occur.

The affluent group, being quite homogeneous, geographically and culturally, also find their relationships in their own group, but they draw their child care providers from groups other than their own. They use similar shopping facilities, support their own private elementary school system, belong to similar clubs. Community and church activities are similar in nature. They are more free to form relationships outside the home and family.

There are many possible reasons why benefits to the child were less important than convenience for both groups. It may be that our instruments did not adequately measure this factor as it is a less definable and measurable quantity than convenience. It also may be that the mother's need for some type of outside activities 
takes precedence regardless of the benefits to the child as long as he appears well cared for.

It might be that the affluent mothers, with their children cared for primarily in the home, feel this is of prime importance in the benefits to the children. These mothers appear to assume they meet their children's needs adequately and that the sitter just provides an instrumental service for the time she is gone. Conversely, the Welfare mothers with little of their need for socialization being met outside of the homes may be concerned with meeting their own needs first. Since they use family members and friends for child care, they have assumed the child received adequate care. Another possibility is that the Welfare mother meets some of her needs for social contacts and relationships from the sitter, as was evidenced by the high satisfaction with the relationship with the sitter. This would indicate the Welfare mother uses the sitter to meet relationship needs as well as to provide child care services.

Generally, it appears that the socioeconomic standing and life circumstances are indirectly reflected in the mother's satisfaction with child care arrangements; the affluent mother, as seen in the Riverdale sample, because she can afford to pay for the kind of ar rangements she wishes to have, and the poverty level mother of the Welfare sample because she can not and must settle for free or the least expensive alternative in child care. The affluent mother, 
having financial security, plus varied and numerous possible outlets for self-expression, has adequate opportunities to find satisfaction in her life style. The poverty mother, with limited income, and in this sample seemingly having few places to go and things to do, expects less of her environment and situation and is likewise satisfied with her life style.

\section{Suggestions for Further Study}

A retesting of the study hypothesis for mothers of two different socioeconomic groups needs to be pursued, controlling for the working or non-working status of the mothers, in order to assess the contributions of working to the feeling of necessity in making ar rangements. It will be remembered that in this current study there were very few working mothers.

Meriting further study are the findings suggesting different ordering of relative satisfaction with convenience and other aspects of the child care arrangement for women under different life cir'cumstances. The difficulty in interpreting this kind of data points to the need for investigating the decision making processes of mothers as they go about seeking substitute child care.

Perhaps in such a context the hypothesis of the relative importance of convenience in the hierarchy of values can be tested. This also would require a more detailed attempt at the measurement 
of mothers' perception of benefits to the child.

\section{Implications for Social Policy}

The extent of financial resources of the families studied seems to have determined the dramatically different patterns of substitute child care used by the two groups of mothers. Money, or the lack of it, is an overriding factor in determining which child care ar rangement can be chosen. This implies that increasing the income of the Welfare family would increase their alternatives for child care. The present Welfare proposals to guarantee an annual income, to allow negative income tax, or to raise the present Welfare grants to a more adequate amount would provide additional money for the general life needs of poverty level mothers and families.

The non-working Welfare mother depends on relatives or friends to provide child care services without cost. This mutual aid system of child care is not consistently available to mothers and imposes more severe constraints on a mother's ability to participate in outside activities than does a monetary system in which child care is purchased with cash. A specific amount added to the Welfare grant for child care without regard for the purpose used would increase the mothers' opportunities for outside activities.

There is a need for child care resources. Based on our sample, very few poverty level families are near a Head Start program 
or a low cost child care center. There was an expressed interest in these resources and a wish that they be made available. Any community action program funded under certain sections of the Economic Opportunity Act, and any public or private nonprofit agency: that meets certain requirements are eligible for financial assistance to implement Head Start programs (Catalog of Federal Assistance Programs, 1967). The funds are available; the responsibility of initiating programs lies at the local community level.

Welfare mothers could be involved in cooperative nursery school or group day care and head start type projects if social agencies helped to organize the projects. As a group, mothers appeared removed from information about obtaining funds for these types of projects. Social agencies could educate the Welfare population. The need for involvement of the people using a program as well as an agency to provide knowledge and structure was indicated.

The evidence of this study supported the belief that, when mothers make child care arrangements, convenience is a salient factor in their attitudes and behavior. The convenience of arrangement has many dimensions; physical proximity, dependability, and flexibility are some which were investigated in the present study. A prime implication of the study is the principle that child care resources must be convenient if they are to be utilized effectively. This means that group care facilities probably have to be 
decentralized geographically for ease of transportation, accessability, and acquaintance in the neighborhood. The principle of convenience also means that group care facilities may have to become flexible in the hours they can be used, including short-term care and evening care. The principle of convenience also implies that the group care must be supplemented by family day care programs and services to improve all kinds of child care arrangements that mothers find convenient to use. 
BIBLIOGRAPHY

1. Catalog of federal assistance programs. O. E. O. Executive Office of the President. Information Center, 1967. 670 p.

2. Child care arrangements of the nation's working mothers: A preliminary report. U. S. Department of Health, Education, and Welfare, Children's Bureau and U. S. Department of Labor, Women's Bureau, 1965. 14 p.

3. Collins, Alice H. Some efforts to improve family day care. Children 12:135-140. July - August 1965.

4. Edwards, Allen L. Techniques of attitude scale construction. New York, Appleton-Century-Croft, 1957. 256 p.

5. Emlen, Arthur C. Field study of the neighborhood family day care system. R-287 (C-1) Progress Report. Mimeo November 1, $1967.36 \mathrm{p}$.

6. Emlen, Arthur C., Alice H. Collins, Eunice L. Watson. Field study of the neighborhood family day care system: A research proposal. Mimeo July 1, 1966. 33 p.

7. Guttman, Louis. The basis of scalogram analysis. In: The American Soldier: Studies in Social Psychology in World War II, Volume 4, Measurement and Prediction. Stauffer, Samuel, et al. Princeton University Press, 1950. p. 60-90.

8. Herzog, Elizabeth. About the poor: Some facts and some fiction. Children's Bureau \#451, U. S. Government Printing Office, 1967. $85 \mathrm{p}$.

9. Hoffman, Martin L. An interview method for obtaining descriptions of parent-child interaction. In: Readings in the Psychology of Parent-Child Relations. New York, Wiley, 1967. p. 57-64.

10. Lewis, Oscar. La vida: A Puerto Rican family in the culture of poverty--San Juan and New York. New York, Random House, 1966. $669 \mathrm{p}$.

11. Maslow, A. H. A theory of human motivation. In: Psychological Review 50:370-376. 1943. 
12. Minturn, Leigh and William W. Lambert. Mothers of six cultures: Antecedents of child rearing. New York, Wiley, 1964. $351 \mathrm{p}$.

13. Perry, Joseph B. The mother substitutes of employed mothers: An exploratory inquiry. Marriage and Family Living. 33:362-367. November 1961.

14. Perry, Gerald et al. Social exchange in private family day care arrangements. Unpublished Master's Thesis. Portland, Portland State College, 1.967. 171 p.

15. Schuessler, Karl F. A note on statistical significance of scalogram. Sociometry 24:312-318. 1961. 


\section{APPENDICES}


APPENDIX A

\section{LETTER TO CASEWORKER}

This letter was sent to caseworkers of the Multnomah County Welfare Department to notify them that it was planned to interview recipients on their caseload.

\section{STATE OF OREGON}

\section{INTEROFFICE MEMO}

TO: Beatrice Bennett, Lewis Hahn, DATE: October 30, 1967 Jeanna Hopkins, Gene Huggins, Helen J. Lierboe, Majorie Smith, Willard Renken

John Burch, Assistant Administrator for Program Services

Attached is a letter from Joan Hansen, who is part of a research group for the Graduate School of Social Work at Portland State College, which explains their project.

Some member of this group outlined in the letter will be contacting your department for current addresses and telephone numbers for those clients included in the sample. They plan to contact the department on Thursday, November 2.

JB:g1.

Attachments 
October 27, 1967

John Burch, Assistant Administrator

Multnomah County Public Welfare Commission

The Oregonian Building

Portland, Oregon 97201

Dear Mr. Burch:

I'm writing this letter in response to our conversation on October 25 at which time you asked that I submit a statement to you about the Portland State College School of Social Work's project on day care arrangements.

A group of six graduate students are studying the day care arrangements being made by people in various financial circumstances. We've chosen as our sample 25 affluent families with young children, and we hope to interview an equal number of families from public assistance rolls. We feel we have a unique approach to this project in that most of the studies done previously have been involved with working mothers. This study is not limited to this population but recognizes instead the reasonable need of families to be away from home for such purposes as recreation and other activities.

Three members of our group, Ruth Hardy, Josephine Gurrola, and myself will be interviewing. Briefly, our interview consists of two parts. The first part is a schedule which elicits information in regard to family composition and other items such as labor saving conveniences, perceived needs for child care, and the various child care resources used by the families. The second part of the interview is involved with asking the respondent to rank according to his degree of agreement forty-four items involved with child care ar rangements.

So far we have seen that the interviews are not at all threatening; on the contrary, the respondents have enjoyed a chance to talk about their experiences with child care. We anticipate a similar good response to our contact with families on public as sistance.

We hope to involve a minimum amount of the caseworkers' time in regard to this study. The extent of involvement should be limited to identifying current addresses of the respondents. Ideally, they would be able to inform their clients by a telephone call that we will be contacting them for an interview. In this telephone call they 
could assure the clients that their answers for even their refusal to answer) would in no way affect their grant, and that their individual responses would remain confidential, known only to the study group and not made available to the caseworker or the Agency.

I am enclosing a list of the families we've chosen by random selection to interview, and their caseworkers. Hopefully, we interviewers will be able to talk with the caseworkers and to make arrangements to interview the families during this week.

Thank you so much for all the help you and your staff have given us so far in this project. If anyone has any questions about the project, I would welcome a telephone call at my home any evening. My phone number is 282-48.91.

Sincerely,

(Mrs.) Joan Hansen

2727 N. E. Si skiyou

Portland, Oregon 97212 
APPENDIX B

LETTER TO RIVERDALE AREA RESPONDENTS

PORTLAND STATE COLLEGE

P. O. Box 751 Portland, Oregon 226-7271

School of Social Work

October 9, 1967

Dear

We are making a study of how parents feel about the child care resources they use. Your name was selected from the Riverdale School Directory to assist us in this study. We need your help and will appreciate your cooperation in answering some questions about the child care arrangements that you use. The questions will take only thirty to forty-five minutes of your time.

The study is under direction of Portland State College School of Social Work. I will call you for an appointment within the next two weeks. Your answers will be kept strictly confidential.

Thank you in advance for your help.

Sincerely,

Research Interviewer 


\section{APPENDIX C}

\section{LETTER TO WELFARE RESPONDENTS}

Dear

A survey is now being made by students in the Portland State College School of Social Work about the child care resources used by families with young children. Your name was chosen to be part of this survey from a list of families receiving public assistance during December, 1966.

One of our group would like to have a brief interview with you in the next few weeks--we would like to discuss your family's need for child care and the resources that you have been able to find.

We want to assure you that your comments will remain confidential. The only contact that we have had with your caseworker has been to get your current address and telephone number. Your individual answers given during our interview will remain known only to our study group and they will not be made available to your caseworker or to the Public Welfare agency. If you do not care to participate in our study, your wish will be respected and your grant will in no way be affected.

We sincerely hope to have your cooperation in our study.

Sincerely yours,

Research Interviewer 
APPENDIX D

QUESTIONNAIRE ABOUT GENERAL LIFE CIRCUMSTANCE

Family Composition

1. Children

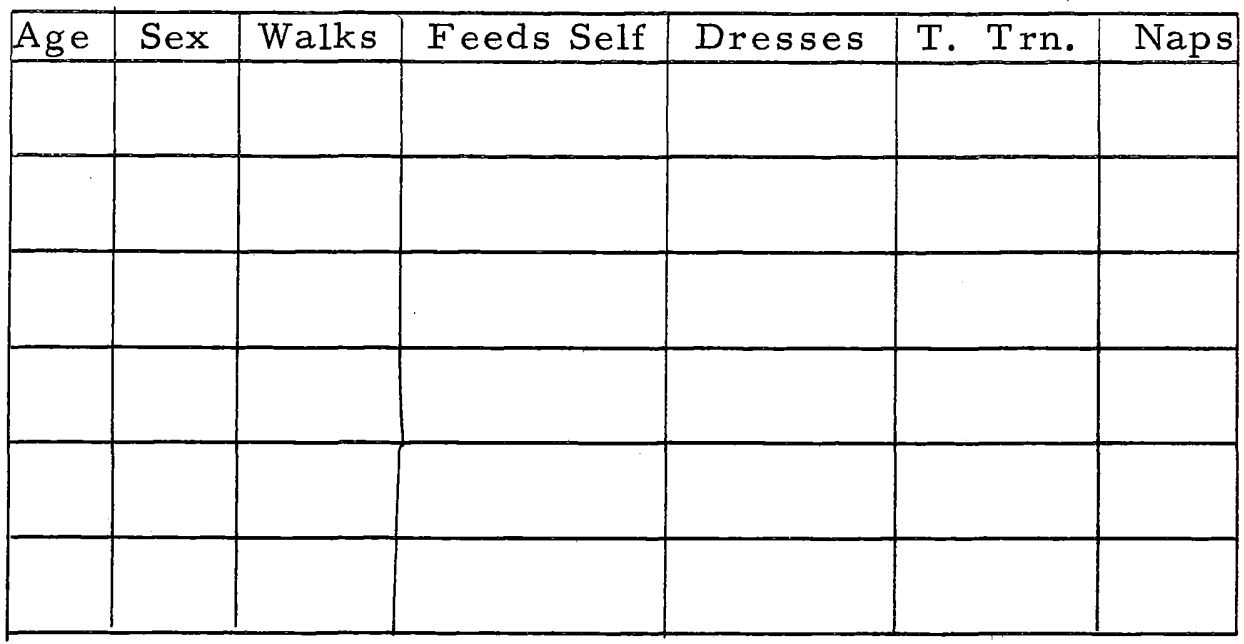

2. Others in Household

\begin{tabular}{|l|l|l|l|l}
\hline Relationship & Age & $\begin{array}{c}\text { Last Year School } \\
\text { Completed }\end{array}$ & Training & Employment \\
\hline & & & & \\
\hline & & & & \\
\hline & & & & \\
\hline & & & & \\
\hline & & & & \\
\hline & & & & \\
\hline
\end{tabular}

3. How long have you lived in this home? 
Page 2 - Questionnaire

4. Which conveniences do you have?

washer

dryer

dishwasher

telephone \#

radio

T.V. \# of

car \# of

bathroom

Write in others they volunteer:

About Child Care Arrangements Used and Needed

5. Do you need a sitter while you a re involved in any of the following activities?

\begin{tabular}{|l|l|l|l|}
\hline Type of Arrangement & Yes or No & Hours & Weekly \\
\hline Recreation & & & \\
\hline Household chores & & & \\
\hline Religious activities & & & \\
\hline Community activities & & & \\
\hline Educational activities & & & \\
\hline Others (list) & & & \\
\hline & & & \\
\hline
\end{tabular}


Page 3 - Questionnaire

6. In regard to these hours, are they

regula $r$

irregular, depending on job to be done

irregular, depending upon your plans

other (explain)

7. If your child is ill, what happens?

you go anyway

you can miss, but not too often

you can miss as much as you need to

other (describe)

8. What do you feel is a reasonable fee to pay?

per hour

per day

per week 
Page 4 - Questionnaire

9. List of Arrangements Which Have Been Used:

\begin{tabular}{|c|c|c|c|c|c|}
\hline Arrangement & $\begin{array}{r}\text { Yes } \\
\text { or No } \\
\end{array}$ & Days & Evenings & $\begin{array}{l}\text { Over } \\
\text { night }\end{array}$ & $\begin{array}{c}\text { As } \\
\text { Needed } \\
\end{array}$ \\
\hline $\begin{array}{l}\text { Nursery school or } \\
\text { day care center }\end{array}$ & & & & & \\
\hline $\begin{array}{l}\text { Relative } \\
\text { your home } \\
\text { their home } \\
\end{array}$ & & & & & \\
\hline $\begin{array}{l}\text { Friend or neighbor } \\
\text { your home } \\
\text { their home } \\
\end{array}$ & & & & & \\
\hline Babysitter in & & & & & \\
\hline Housekeeper or maid & & & & & \\
\hline $\begin{array}{l}\text { Child care service } \\
\text { newspaper or } \\
\text { employment agency }\end{array}$ & & & & & \\
\hline $\begin{array}{l}\text { Child cares for self } \\
\text { (neighbors available) }\end{array}$ & & & & & \\
\hline Other sibling & & & & & \\
\hline Others (1ist) & & & & & \\
\hline & & & & & \\
\hline
\end{tabular}

Of all the types of care you have used, which one seemed most satisfactory?

10. Do you have an easy or hard time getting a sitter? 
Page 5 - Questionnaire

11. What made it so?

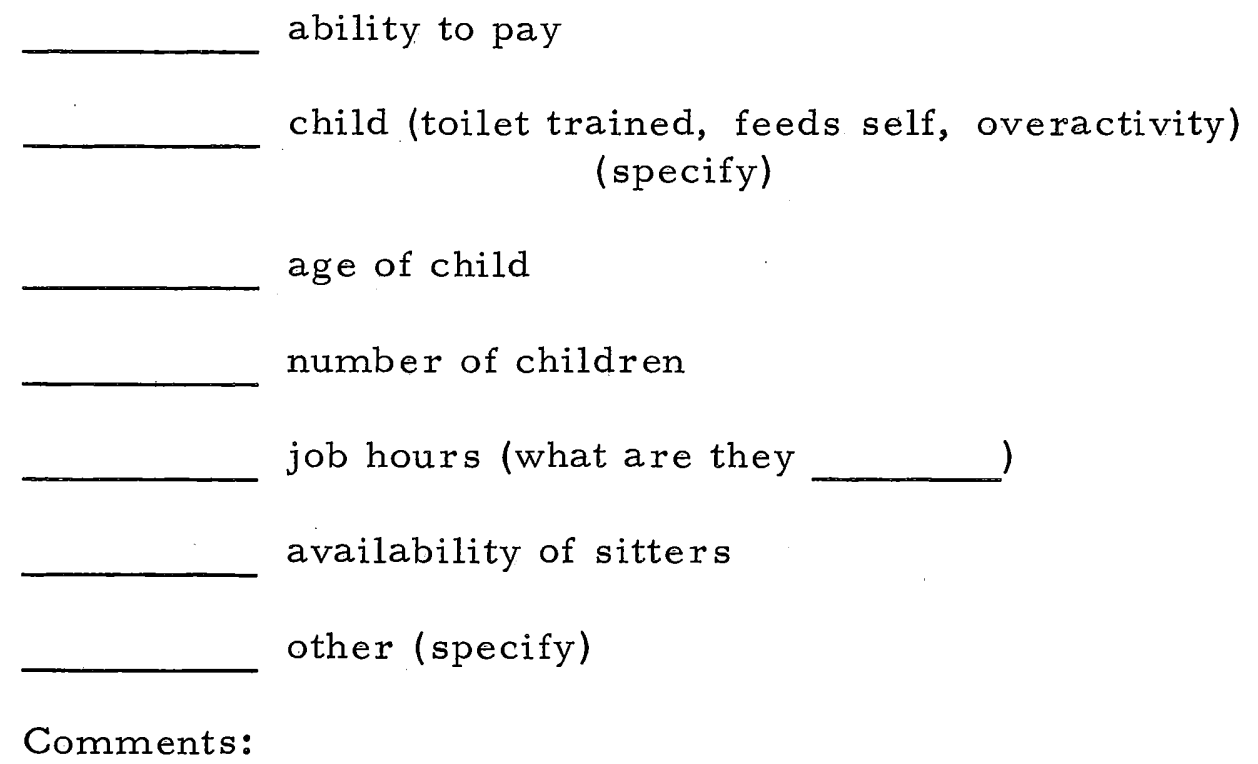

Current Most Used Arrangement:

12. What is your current most used arrangement?

13. What do you like most about it?

14. What do you find wrong with it?

15. How did you happen to make this arrangement? 
Page 6 - Questionnaire

Facts About Arrangement:

16. How long have you had it?

Who transports your child(ren)?

How much do you pay?

Is the sitter

close to your home

close to your destination

out of the way

not out of the way

Is the sitter available

any time

most of the time

only when scheduled

Is there anything you have to take to the sitter's? 
APPENDIX E

PRETEST OF SCALE ITEMS

\section{INSTRUCTIONS:}

Enclosedis a set of cards on which are written statements we hope to use as part of our research project on child care arrangements.

As an impartial judge, we are asking you to rate these items, as to how well you feel they fit into one or more of four categories. The four categories are:

DEPENDABILITY of the arrangement as seen by the mother, i.e., reliability, availability, following of instructions, etc.

CONVENIENCE of the arrangement as seen by the mother related to time, distance or place of the child care arrangement.

BENEFITS TO CHILD in the arrangement as seen by the mother, i.e., : training, interpersonal relationships between child and sitter, or child and peers, etc.

MOTHER'S RELATIONSHIP to child care person. The personal emotional satisfaction the mother receives from knowing the sitter, i. e., : friendship.

On the attached sheet of paper please rate the items under

each category, either:

0 does not fit

1 slightly

2 partially

3 perfectly

Ud undecided

Thank you for your help. 
Ten judges were used in an attempt to segregate the items into four discrete content areas. They were told to mark the content areas that were most suitable for the items: 0 (does not fit), 1 (slightly), 2 (partially), 3 (perfectly), UD (undecided). Below are the average responses to each item. Convenience and dependability were combined in one scale. Percentage of agreement equals . 94.

TABLE XVII

JUDGES' RATING OF ITEM CONTENT

\begin{tabular}{rrrrrl}
\hline & $\begin{array}{c}\text { Conven } \\
\text { Item }\end{array}$ & $\begin{array}{c}\text { Depend } \\
\text { ability }\end{array}$ & $\begin{array}{c}\text { Benefits } \\
\text { to } \\
\text { Child }\end{array}$ & $\begin{array}{c}\text { Relation- } \\
\text { ship to } \\
\text { Sitter }\end{array}$ & $\begin{array}{c}\text { Category } \\
\text { Chosen }\end{array}$ \\
\hline 1 & 0 & .5 & 2.9 & .6 & B. C. \\
2 & 1.1 & 2.6 & .8 & 1.0 & Dep. \\
3 & 0 & .6 & 2.5 & 1.0 & B. C. \\
4 & .1 & .5 & 1.8 & 1.0 & B. C. \\
5 & .4 & .9 & 2.9 & 1.2 & B. C. \\
6 & .1 & .2 & .5 & 2.7 & R. S. \\
8 & 2.3 & .5 & .3 & .5 & Con. \\
9 & .2 & .4 & .4 & 2.5 & R. S. \\
11 & 1.7 & .4 & 0 & .6 & Con. \\
12 & .8 & .6 & 2.6 & 0 & B. C. \\
13 & .7 & .2 & 1.4 & .6 & B. C. \\
14 & 1.6 & .5 & .6 & .1 & Con. \\
15 & .7 & 2.8 & 1.1 & .9 & Dep. \\
16 & .8 & 2.4 & .7 & 1.0 & Dep. \\
17 & .6 & 1.6 & 2.3 & 1.4 & B. C. \\
18 & .6 & .7 & .2 & 2.9 & R. S. \\
19 & .5 & .5 & 1.1 & 2.6 & R. S. \\
21 & 0 & .3 & 2.2 & 1.1 & B. C. \\
22 & .1 & .5 & 2.5 & 1.2 & B. C. \\
24 & .3 & 1.1 & 2.2 & 1.1 & B. C. \\
26 & .5 & 1.0 & 1.2 & 2.0 & R. S. \\
28 & 1.1 & 1.9 & .9 & .7 & Dep. \\
29 & 2.0 & 1.7 & 1.0 & .9 & Con. \\
31 & 2.5 & 1.2 & .8 & .5 & Con.
\end{tabular}


TABLE XVII (continued)

\begin{tabular}{lccccc}
\hline Item & $\begin{array}{c}\text { Conven } \\
\text { ience }\end{array}$ & $\begin{array}{c}\text { Depend } \\
\text { ability }\end{array}$ & $\begin{array}{c}\text { Benefits } \\
\text { to } \\
\text { Child }\end{array}$ & $\begin{array}{c}\text { Relation- } \\
\text { ship to } \\
\text { Sitter }\end{array}$ & $\begin{array}{c}\text { Category } \\
\text { Chosen }\end{array}$ \\
\hline 32 & 1.2 & .6 & .1 & 1.5 & Eliminated \\
35 & 1.1 & .8 & .3 & .5 & Con. \\
37 & .7 & 1.0 & .4 & 2.6 & R. S. \\
38 & .6 & .6 & 1.5 & .2 & Eliminated \\
39 & .8 & .9 & 2.6 & .7 & B. C. \\
40 & .7 & 1.0 & 2.2 & .5 & B. C. \\
41 & 1.0 & 2.8 &. .6 & .8 & Dep. \\
42 & .4 & 2.4 & .9 & 1.4 & Dep. \\
43 & 0 & .9 & .4 & 2.7 & R. S. \\
44 & .8 & .9 & .6 & 2.4 & R.S. \\
& & & & & \\
\hline
\end{tabular}




\section{APPENDIX F}

\section{SCALE ITEMS AS PRESENTED TO RESPONDENTS}

1. My sitter understands my child's moods.

2. My sitter always does what she says she will do.

3. She doesn't give the children enough to do.

4. I have trouble with my child because the sitter spoils him.

5. She takes a real interest in my child.

6. My sitter and I sit and talk to each other for hours.

7. It's hard to find a babysitter who really enjoys taking care of the children.

8. I feel I am paying a reasonable fee for the care of my child.

9. She takes an interest in me personally.

10. If I want a sitter, I have to take what I can get.

11. Most babysitters want more money than I can pay.

12. My child picks up bad habits at the sitter's.

13. It bothers me that my sitter doesn't have enough play things for the children.

14. The babysitter lives too far away to be convenient.

15. When an emergency arises at the sitter's, I'm sure it will be handled properly.

16. I would be happier if I could depend on my babysitter more.

17. I like the way she keeps the children clean.

18. I get tired of her telling me her problems. 
19. Sometimes I'm afraid she's coming between me and my child.

20. I am careful not to impose on my sitter.

21. My child learns some important things that he wouldn't learn at home by being with this sitter.

22. My sitter and my child enjoy each other.

23. I ovouldn't dare do anything to upset my sitter.

24. My child is learning how to do things for himself at the babysitter's.

25. You have to put up with a lot in order to keep a sitter.

26. Sometimes she ignores my instructions.

27. I make every effort to patch up misunderstandings that may arise with my sitter.

28. I can drop my child off at the sitter's anytime I need to.

29. I can count on my sitter to continue to take care of my child when I'm late.

30. Getting someone you can depend on is very difficult.

31. If I ever have to change my plans, she is very flexible about it.

32. I only see my sitter when I pick up or deliver my child.

33. I simply won't keep a sitter who won't follow instructions.

34. Keeping a sitter is hard.

35. I think that babysitters try to charge too much for their services.

36. If a sitter can't be flexible, I won't hire her.

37. I feel she takes advantage of me.

38. I chose this sitter because of the other children my child would play with there. 
39. I wish my sitter would spend more time doing things with my child.

40. I worry that my sitter sometimes leaves my child with someone else.

41. I can count on my sitter to let me know if she plans to go anywhere out of the ordinary with my child.

42. She's someone you can count on in an emergency.

43. She often takes time to sit down and talk.

44. She is considerate of me. 


\section{APPENDIX G}

\section{INSTRUCTIONS TO INTERVIEWERS}

The following is a sample interview for completing the Day Care Schedule. It is written in outline form, for those who were to do the interviewing felt that they would conduct their best interview if the content were structured but the wording left flexible.

I. Introduction

Interviewer introduces self to respondent and asks for cooperation in completing schedule. Tells how name was obtained (Riverdale Register or Public Welfare). Explains what we are doing and why, and outlines the procedure to be followed in completing the schedule: (two parts, face sheet and cards). Stresses confidentiality of respondent and response.

Any interpretation of the purpose of this study is limited to

"an overview of the kinds of day care arrangements made by people of various circumstances." To that end we need to know a few facts about the families, such as number of children, family activities which might require child care, kinds of child care resources found, and some idea about the mother's satisfaction with the arrangements she has made for child care.

Interviewer asks for any questions in regard to the interview before continuing. 
II. Refer to Schedule

1. Talk about the children first:

How many do they have?

What are their ages? (developmental information is asked for and appropriate boxes are checked on schedule)

\begin{tabular}{|c|c|c|c|c|c|c|}
\hline Age & Sex & Walks & Feeds Self & Dresses Self & T. Trn. & Naps \\
\hline & & & & & & \\
\hline & & & & & & \\
\hline
\end{tabular}

2. Who else lives in the home?

Any other children or adults?

(Probes for schooling, training, and/or employment of adults)

\begin{tabular}{|l|l|l|l|}
\hline $\begin{array}{l}\text { Relationship } \\
\text { to Respondent }\end{array}$ & Age & $\begin{array}{c}\text { Last Year School } \\
\text { Completed }\end{array}$ & $\begin{array}{c}\text { Training and/or } \\
\text { Employment }\end{array}$ \\
\hline & & & \\
\hline & & & \\
\hline
\end{tabular}

3. About living arrangements. How long at this address?

4. About conveniences (probe and check where convenient on schedule)

washer dryer etc。

5. About arrangements for child care made in past or presently.

Was a sitter ever needed for any of the following activities: How much (hrs./wk.) have any of them been used?

Were all of the possibilities included? 


\begin{tabular}{|l|l|l|l|}
\hline Type of Arrangement & yes/no & hours & week \\
\hline Employment & & & \\
\hline Recreation & & & \\
\hline Etc. & & & \\
\hline
\end{tabular}

6. Were the hours child care was needed regular, irregular, or what? How described? (Probe and check where appropriate on schedule)

7. What is done in the event of emergency of child, such as illness? (Probe and check where appropriate on schedule)

8. What respondent thinks is reasonable fee to pay for child care.

9. How has respondent usually found the child care arrangement?

10. What of the various kinds of child care arrangements has respondent used in past? When have these been available to her?

\begin{tabular}{|l|l|l|l|l|l|l|}
\hline Arrangement & $\begin{array}{c}\text { Yes } \\
\text { No }\end{array}$ & Days & $\begin{array}{c}\text { Days and } \\
\text { Evenings }\end{array}$ & Evenings & $\begin{array}{c}\text { Over } \\
\text { night }\end{array}$ & $\begin{array}{c}\text { As } \\
\text { Needed }\end{array}$ \\
\hline nursery s chool & & & & & & \\
\hline $\begin{array}{c}\text { or } \\
\text { day care center }\end{array}$ & & & & & & \\
\hline relative & & & & & & \\
\hline etc. & & & & & & \\
\hline
\end{tabular}

Of all the arrangements used, which was most satisfactory?

11. Does respondent find it difficult or easy to find a sitter? (Probe for reasons why, and check where appropriate on schedule)

ability to pay child factors etc. 
12. Have respondent identify most used current arrangement. Explain that it is this arrangement which will be referred to in all succeeding questions.

13. What is liked about this arrangement (open ended)?

14. What is not liked about it (open ended)?

15. Other facts about the arrangement requested:

How long has she had it?

Who transports the child(ren)?

Etc.

III. The Cards

Interviewer explains procedure in using the cards. Points out that responses should refer to the most used current arrangement. Cards should not be dwelt on too long, most correct answer should dictate choice in case of ambiguity or indecision.

IV. Closure

Mother thanked for cooperation.

She is asked if she would be interested in follow-up interview we hope to have with some of our respondents, at which time we could go into more depth about their own specific child care arrangements and how they feel about them. Three alternatives:

Yes, and name can be attached to schedule for reference.

Yes, but don't associate name and schedule (put name and address on separate card, if this is the request)

No.

V. Observation 


\section{APPENDIX H}

THANK-YOU LETTER

PORTLAND STATE COLLEGE

School of Social Work

December 19, 1967

Dear Mrs.

Thank you for letting me interview you as part of the Child Care Research Project. We appreciate the help that you have given us.

The Project will be completed this Spring after which I would like to send you a small report on our findings.

Very truly yours,

Research Interviewer 
APPENDIX I

FAMILY COMPOSITION

TABLE XVIII

SIZE OF FAMILIES

\begin{tabular}{lcc}
\hline & Riverdale & Welfare \\
\hline Mean family size & 3.9 & 4.1 \\
Range & $1-6$ & $1-8$ \\
& 79 children & 83 children \\
\hline
\end{tabular}

TABLE XIX

AGE OF FATHERS

\begin{tabular}{lcc}
\hline & Riverdale & Welfare \\
\hline Median age & 37 & 29 \\
Range & $31-45$ & $21-61$ \\
\hline
\end{tabular}

TABLE XX

EDUCATIONAL LEVEL OF FATHERS

\begin{tabular}{lcc}
\hline & Riverdale & Welfare \\
\hline Some college & 18 & 1 \\
No college & 2 & 8 \\
& $\mathrm{n}=20$ & $\mathrm{n}=9$ \\
\hline
\end{tabular}

(Six Welfare fathers did not enter high school.) 
TABLE XXI

TRAINING OF RIVERDALE FATHERS

Training

Number

Business Administration

Engineer

7
3
2
2
1
1
1
1
$N=\frac{2}{20}$

TABLE XXII

EMPLOYMENT OF RIVERDALE FATHERS

Employment

Number

Owner or manager of business firm

5

Finance

5

Medicine

2

Property management and/or development

2

Engineer

2

Sales

Education

Law

Architecture

$$
\mathrm{N}=\frac{1}{20}
$$


TABLE XXIII

EMPLOYMENT OF FATHERS

\begin{tabular}{lcc}
\hline & Riverdale & Welfare \\
\hline Percent employed & 100 & 44 \\
Percent not employed & $\frac{0}{100 \%}$ & $\frac{56}{100 \%}$ \\
\hline
\end{tabular}

TABLE XXIV

AGE OF MOTHERS

\begin{tabular}{lcc}
\hline & Riverdale & Welfare \\
\hline Median age & 34 & 26 \\
Range & $27-41$ & $19-43$ \\
\hline
\end{tabular}

TABLE XXV

EDUCATION OF MOTHERS

\begin{tabular}{lcc}
\hline & Riverdale & Welfare \\
\hline Some college & 17 & 1 \\
No college & $N=\frac{3}{20}$ & $N=\frac{19}{20}$ \\
\hline
\end{tabular}

(Fifteen Welfare mothers did not enter high school). 
ENVIRONMENTAL FACTORS CONTRIBUTING TO CONVENIENCE

TABLE XXVI

CHECK LIST OF CONVENIENCES

\begin{tabular}{lcc}
\hline & Riverdale & Welfare \\
\hline & 20 & 0 \\
More than one bathroom & 20 & 10 \\
Washer & 20 & 6 \\
Dryer & 20 & 0 \\
Dishwasher & 20 & 17 \\
Television & 6 & 0 \\
Second Television & 20 & 10 \\
Auto & 18 & 1 \\
Second Auto & 20 & 7 \\
Telephone & & \\
\hline
\end{tabular}

TABLE XXVII

CONVENIENCES VOLUNTEERED BY RESPONDENTS

Riverdale

Other appliances

Cleaning help

Architecture of home

Neighborhood features

Special child care arrangement

Ages of children

Relatives to help

School

Music

Toys, play equipment

Playpen, furnishings
Welfare

$\begin{array}{rr}11 & 1 \\ 5 & 0 \\ 4 & 6 \\ 3 & 1 \\ 3 & 0 \\ 0 & 2 \\ 1 & 1 \\ 0 & 1 \\ 1 & 1 \\ 1 & 4 \\ 0 & 2\end{array}$


TABLE XXVIII

LENGTH OF RESIDENCE AT CURRENT ADDRESS

\begin{tabular}{lccccc}
\hline & $\begin{array}{c}0-2 \\
\text { years }\end{array}$ & $\begin{array}{c}21 / 2-4 \\
\text { years }\end{array}$ & $\begin{array}{c}41 / 2-6 \\
\text { years }\end{array}$ & $\begin{array}{c}61 / 2-8 \\
\text { years }\end{array}$ & $\begin{array}{c}81 / 2+ \\
\text { years }\end{array}$ \\
\hline Riverdale & 3 & 8 & 2 & 2 & 5 \\
Welfare & 17 & 1 & 0 & 1 & 1 \\
\hline
\end{tabular}

CHILD CARE ARRANGEMENTS

TABLE XXIX

HISTORICAL DATA:

CHILD CARE ARRANGEMENTS USED

Riverdale Welfare

Relative in home

Relative out of home

Friend, neighbor in home

Friend, neighbor out of home

Sitter in home

Sitter out of home

Housekeeper, maid

Nursery school, day care center

Child care service

Older sibling

Child cares for self

$\begin{array}{rr}11 & 12 \\ 12 & 14 \\ 6 & 12 \\ 17 & 13 \\ 20 & 13 \\ 2 & 1 \\ 14 & 3 \\ 19 & 6 \\ 13 & 1 \\ 10 & 6 \\ 13 & 9\end{array}$


TABLE XXX

CURRENT CHILD CARE ARRANGEMENT

\begin{tabular}{lcc}
\hline & Riverdale & Welfare \\
\hline Sitter in & 10 & 0 \\
Housekeeper in days & 3 & 0 \\
Live-in sitter (non-relative) & 4 & 0 \\
Siblings & 2 & 1 \\
Relatives in & 1 & 11 \\
Neighbors in & 0 & $\mathrm{~N}=\frac{8}{20}$ \\
\end{tabular}

TABLE XXXI

\section{CURRENT CHILD CARE NEED}

\begin{tabular}{|c|c|c|c|c|}
\hline \multirow[b]{2}{*}{ Activity } & \multicolumn{2}{|c|}{ Riverdale families } & \multicolumn{2}{|c|}{ Welfare families } \\
\hline & $\begin{array}{l}\text { No. of } \\
\text { Mothers }\end{array}$ & $\begin{array}{c}\text { Hours } \\
\text { per week }\end{array}$ & $\begin{array}{l}\text { No. of } \\
\text { Mothers }\end{array}$ & $\begin{array}{c}\text { Hours } \\
\text { per week }\end{array}$ \\
\hline Recreation & 19 & 153 & 19 & 60.5 \\
\hline Employment & 5 & 73 & 0 & 0 \\
\hline Household chores & 7 & 12.5 & 10 & 16.5 \\
\hline Religious activities & 3 & 4.5 & 2 & 3 \\
\hline Community activities & 14 & 94.5 & 3 & 5 \\
\hline Education & 18 & 15 & 1 & 2 \\
\hline Medical needs & 1 & 4 & 5 & 14 \\
\hline Children's activities & 3 & 6 & 0 & 0 \\
\hline
\end{tabular}


TABLE XXXII

HOW CURRENT ARRANGEMENT LOCATED

\begin{tabular}{lcc}
\hline Contact & Riverdale & Welfare \\
\hline & 5 & 4 \\
Neighbors & 7 & 0 \\
Agencies & 1 & 0 \\
Schools & 2 & 5 \\
Friends & 1 & 0 \\
Relatives & 3 & 11 \\
Immediate family & $\frac{1}{20}$ & $\mathrm{~N}=\frac{0}{20}$ \\
Church & $\mathrm{N}=\frac{}{20}$ \\
\hline
\end{tabular}

TABLE XXXIII

TRANSPORTATION PATTERNS IN CHILD CARE ARRANGEMENT

\begin{tabular}{lcc} 
Method & Riverdale & Welfare \\
\hline Sitter to child's home & 12 & 8 \\
Child to sitter's home & 0 & 6 \\
Live-in sitter & 6 & 5 \\
Mother drives sitter to home & 2 & 0 \\
Child transports self & $\mathrm{N}=\frac{0}{20}$ & $\mathrm{~N}=\frac{1}{20}$ \\
\hline
\end{tabular}


TABLE XXXIV

MOTHERS' PERCEPTION OF REASONS FOR EASE

IN MAKING CHILD CARE ARRANGEMENTS

\begin{tabular}{lcc}
\hline & & \\
Reason & Riverdale & Welfare \\
\hline & 3 & 1 \\
Ability to pay & 5 & 3 \\
Child no problem & 5 & 4 \\
Age of children & 4 & 1 \\
Number of children & 3 & 1 \\
No special needs of children & 10 & 11 \\
Sitter is available & & \\
\hline
\end{tabular}

TABLE XXXV

MOTHERS' PERCEPTION OF REASONS FOR DIFFICULTY IN MAKING CHILD CARE ARRANGEMENTS

\begin{tabular}{lll}
\hline Reason & Riverdale & Welfare \\
\hline & 2 & 3 \\
Cannot pay & 1 & 0 \\
Child a problem & 3 & 0 \\
Age of children a problem & 3 & 1 \\
Number of children a problem & 2 & 3 \\
Needs of child a problem & 6 & 2 \\
No sitter available & & \\
\hline
\end{tabular}




\section{APPENDIX $J$}

This appendix includes tables showing the relationship between the indicants of child care necessity and satisfaction with the arrangement.

TABLE XXXVI

SATISFACTION WITH THE ARRANGEMENT BY CHILD CARE NECESSITY

\begin{tabular}{|c|c|c|c|c|}
\hline$\overline{\text { Child }}$ & \multicolumn{2}{|c|}{ Riverdale } & \multicolumn{2}{|c|}{ Welfare } \\
\hline Care & High* & $\overline{\text { Low }}$ & High* & $\overline{\text { Low }}$ \\
\hline Necessity & Satis. & Satis. & Satis. & Satis. \\
\hline High & 5 & 3 & 5 & 2 \\
\hline Low & 5 & 7 & 6 & 7 \\
\hline
\end{tabular}

TABLE XXXVII

SATISFACTION WITH THE ARRANGEMENT BY NUMBER OF CHILDREN IN THE FAMILY

\begin{tabular}{|c|c|c|c|c|}
\hline \multirow{3}{*}{$\begin{array}{l}\text { Number of } \\
\text { children } \\
\text { in family } \\
\end{array}$} & \multicolumn{2}{|c|}{ Riverdale } & \multicolumn{2}{|c|}{ Welfare } \\
\hline & $\overline{\text { High }}$ & Low & High & $\overline{\text { Low }}$ \\
\hline & Satis. & Satis. & Satis. & Satis. \\
\hline 1 & 1 & 0 & 1 & 1 \\
\hline 2 & 1 & 1 & 0 & 1 \\
\hline 3 & 1 & 3 & 4 & 0 \\
\hline 4 & 2 & 2 & 4 & 1 \\
\hline 5 & 5 & 3 & 0 & 4 \\
\hline 6 & 0 & 1 & 2 & 0 \\
\hline 7 & 0 & 0 & 0 & 1 \\
\hline 8 & 0 & 0 & 0 & 1 \\
\hline
\end{tabular}


TABLE XXXVIII

SATISFACTION WITH THE ARRANGEMENT BY NUMBER OF CHILDREN UNDER SIX IN THE FAMILY

\begin{tabular}{lccccc}
\hline $\begin{array}{l}\text { Number of } \\
\begin{array}{l}\text { Children } \\
\text { Under } 6\end{array}\end{array}$ & $\begin{array}{c}\text { High } \\
\text { Satis. }\end{array}$ & $\begin{array}{r}\text { Low } \\
\text { Satis. }\end{array}$ & & $\begin{array}{c}\text { High } \\
\text { Satis. }\end{array}$ & $\begin{array}{c}\text { Low } \\
\text { Satis. }\end{array}$ \\
\hline 0 or 1 & 3 & 12 & 1 & 1 \\
2, 3, or 4 & 4 & 1 & 10 & 8 \\
\hline
\end{tabular}

TABLE XXXIX

SATISFACTION WITH THE ARRANGEMENT BY NUMBER OF HOURS PER WEEK OF SUBSTITUTE CHILD CARE

\begin{tabular}{lcc}
\hline $\begin{array}{l}\text { Number of } \\
\text { Hours }\end{array}$ & \multicolumn{2}{c}{ Satisfaction } \\
\hline Riverdale & 5 & Low \\
\hline$Q_{1}(41,38,36,31,29$ hours $)$ & 1 & 0 \\
$Q_{2}(22,22,21,18,15$ hours $)$ & 0 & 4 \\
$Q_{3}(15,14,14,10,8$ hours $)$ & 4 & 5 \\
$Q_{4}(6,5,5,4,1$ hours $)$ & & 1 \\
Welfare & 3 & \\
$Q_{1}(20,11,10,9,7$ hours $)$ & 2 & 3 \\
$Q_{2}(6,6,5,5,5$ hours $)$ & 2 & 3 \\
$Q_{3}(5,4.5,4,3,2.5$ hours $)$ & 4 & 1 \\
$Q_{4}(2,1,1,1,1$ hours $)$ & & \\
\hline
\end{tabular}


TABLE XL

SATISFACTION WITH THE ARRANGEMENT BY CHILD CARE RESOURCES IN HOUSEHOLD

\begin{tabular}{ccccc}
\hline $\begin{array}{l}\text { Live-in } \\
\text { Child Care } \\
\text { Resource }\end{array}$ & $\begin{array}{c}\text { High } \\
\text { Satis. }\end{array}$ & $\begin{array}{c}\text { Low } \\
\text { Satis. }\end{array}$ & $\begin{array}{c}\text { High } \\
\text { Satis. }\end{array}$ & $\begin{array}{r}\text { Low } \\
\text { Satis. }\end{array}$ \\
\hline Yes & 2 & 5 & 5 & 7 \\
No & 8 & 5 & 6 & 2 \\
\hline
\end{tabular}

